\title{
The Max-Planck-Institute global ocean/sea ice model with orthogonal curvilinear coordinates.
}

\author{
S. J. Marsland ${ }^{*}$ H. Haak $\dagger$ J. H. Jungclaus \\ M. Latif $§$ and F. Röske I \\ Max-Planck-Institut für Meteorologie, \\ Bundesstr. 55, 20146 Hamburg, Germany
}

\begin{abstract}
The Hamburg Ocean Primitive Equation (HOPE) model has undergone significant development in recent years. Most notable is the treatment of horizontal discretisation which has undergone transition from a staggered $\mathrm{E}$ grid to an orthogonal curvilinear C-grid. The treatment of subgridscale mixing has been improved by the inclusion of a new formulation of bottom boundary layer (BBL) slope convection, an isopycnal diffusion scheme, and a Gent and McWilliams style eddy-induced mixing parameterisation. The model setup described here has a north pole over Greenland and a south pole on the coast of the Weddell Sea. This gives relatively high resolution in the sinking regions associated with the thermohaline circulation. Results are presented from a 450 year climatologically forced integration. The forcing is a product of the German Ocean Model Intercomparison Project and is derived from the ECMWF re-analysis. The main emphasis is on the model's representation of key quantities that are easily associated with the ocean's role in the global climate system. The global and Atlantic northward poleward heat transports have peaks of 1.43 and $0.84 \mathrm{PW}$, at 18 and $21^{\circ} \mathrm{N}$ respectively. The Atlantic meridional overturning streamfunction has a peak of $15.7 \mathrm{~Sv}$ in the North Atlantic and an outflow of $11.9 \mathrm{~Sv}$ at $30^{\circ} \mathrm{S}$. Comparison with a simulation excluding BBL shows that the scheme is responsible for up to a $25 \%$ increase in North Atlantic heat transport, with significant improvement of the depths of convection in the Greenland, Labrador and Irminger Seas. Despite the improvements, comparison with observations shows the heat transport still to be too weak. Other outstanding problems include an incorrect Gulf Stream pathway, a too strong Antarctic Circumpolar Current, and a too weak renewal of Antarctic Intermediate Water. Nevertheless, the model has been coupled to the atmospheric GCM ECHAM5 and run successfully for over 250 years without any surface flux corrections.
\end{abstract}

Keywords: GENERAL CIRCULATION; OCEAN; SEA ICE; PRIMITIVE EQUATION; CONFORMAL MAPPING; GLOBAL

\footnotetext{
*marsland@dkrz.de (Simon Marsland)

thaak@dkrz.de (Helmuth Haak)

*jungclaus@dkrz.de (Johann Jungclaus)

§latif@dkrz.de (Mojib Latif)

Troeske@dkrz.de (Frank Röske)
} 


\section{Introduction}

Primitive equation ocean general circulation models (OGCMs) have been the subject of intensive research over recent decades. Since their inception (e.g. Bryan, 1969) OGCMs have been used as a numerical laboratory for oceanic investigation and more recently as a component of coupled ocean/atmosphere GCMs used in climate research. Major developments have included the introduction of sigma-level and isopycnal vertical coordinate systems, improved parameterisations of subgridscale processes, improved numerical schemes for the solution of the discretised system, and the increasing availability of computational resources to name a few. A thorough description of OGCM development is beyond the scope of this paper. For an overview of the current state-of-the-art of OGCMs used in climate research see Griffies et al. (2000).

The core of the Hamburg Ocean Primitive Equation (HOPE) model was written by Ernst Maier-Reimer at the Max-Planck-Institut für Meteorologie (MPIfM). In recent years the HOPE model has undergone significant development. Using the nomenclature of Arakawa and Lamb (1977) the spatial arrangement of scalar and vector variables in HOPE was originally formulated on an E-grid. The HOPE model is documented by Wolff et al. (1997). A detailed description of the mean state of the HOPE model integrated with climatological forcing is given by Legutke and MaierReimer (1999). HOPE has previously been used in both global (Drijfhout et al., 1996; Stössel, 1997; Legutke et al., 1997; Stössel et al., 1998; Kim and Stössel, 1998; Rodgers et al., 2000) and regional studies (Marsland and Wolff, 1998, 2001). It is also the ocean component of the ECHAM/HOPE coupled ocean-atmosphere model (Latif et al., 1994; Stockdale et al., 1994; Latif and Barnett, 1994, 1996; Frey et al., 1997; Grötzner et al., 1998; Legutke and Voss, 1999; Venzke et al., 2000), where ECHAM (Roeckner et al., 1996) is the Hamburg version of the European Centre for Medium Range Weather Forecasting (ECMWF) atmospheric model.

There are two features of the $\mathrm{C}$-grid that may be considered advantageous to the E-grid. Firstly, the C-grid is more computationally efficient than the staggered Egrid. That is, a higher horizontal resolution can be achieved with the same number of grid points. Secondly, the E-grid model required additional horizontal numerical diffusion to inhibit the tendency of the two staggered subgrids to diverge from each other. A C-grid version of the HOPE model has been used to study the combined effects of tides and circulation on the earth's rotation (Thomas et al., 2001). Here we present the latest HOPE (C-grid) version, which will be referred to hereafter as version 1 of the Max-Planck-Institute ocean model (MPI-OM-1).

Arbitrary placement of the model's poles on an orthogonal curvilinear grid offers two major advantages over conventional latitude-longitude grids. Firstly, placement of the poles over land removes the numerical singularity associated with convergence of meridians at the geographical north pole. Secondly, the choice of non-diametric poles allows for the construction of regionally high-resolution models that maintain a global domain and thus avoid the problems associated with either open or closed boundaries. Recently, the use of orthogonal curvilinear grids has become increasingly popular in both ocean and atmosphere models (see Griffies et al., 2000, for a list of orthogonal curvilinear OGCMs currently used for climate research).

Notable with respect to the HOPE model versions previously used for MPIfM coupled climate simulations are the new parameterisations of subgridscale processes that have been incorporated into the current version of the MPI-OM-1 model. 
Firstly, a new bottom boundary layer (BBL) slope convection scheme has been included that allows for a better representation of the flow of statically unstable dense water masses over sills and off shelves. Secondly, harmonic horizontal diffusion of the thermohaline fields has been replaced by an isopycnal scheme. Isopycnal diffusion is preferable since it accounts for the observation that tracers are basically mixed along isopycnals. Thirdly, eddy-induced tracer transport has been included by the implementation of a Gent and McWilliams (Gent et al., 1995) style parameterisation. Fourthly, so-called convective adjustment has been replaced by a parameterisation using enhanced vertical diffusion. This allows for the introduction of a time dependent oceanic response to static instability.

In addition to the new features described here the MPI-OM-1 model retains many of the desirable features of the HOPE model. Both models are formulated with a free surface elevation and fully resolve the discretised bottom topography by way of partial grid cells at the lower boundary. The dynamics of sea ice are formulated using a viscous-plastic rheology following Hibler (1979). The thermodynamics relate sea ice thickness changes to a balance of radiant, turbulent and oceanic heat fluxes. The sea ice coverage is fractional within grid cells and is related to the thickness according to subgridscale parameterisation of lateral versus vertical ablation and accretion following Stössel (1992). The considerable insulating effects of snow accumulation on sea ice are included, along with snow-ice formation when the snow/ice interface sinks below the sea level due to snow loading.

Following in the style of recent similar reports by other groups (e.g. Gent et al., 1998; Bleck, 2002), the purpose of this paper is to inform the numerical oceanographic community of the state-of-the-art in ocean model development at the MPIfM. The primitive equations, the ocean subgridscale parameterisations, the sea ice dynamics and thermodynamics, and the model timestepping are described in Section 2. Implementation and application of the orthogonal curvilinear grid is described in Section 3. The German Ocean Model Intercomparison Project (OMIP) forcing climatology, along with descriptions of the treatment of heat, freshwater and momentum forcing, are introduced in Section 4. Results from MPI-OM-1 integrations with OMIP climatological forcing on the standard MPIfM global grid for climate studies are presented in Section 5. The mean state for years 400-450 of a control integration is presented in Section 5.1, and the sensitivity to exclusion of the BBL transport scheme for a 100 year integration is described in Section 5.2. A discussion of the results and also of concurrent developments of the MPI-OM-1 model in both ocean-only and coupled modes is given in Section 6 .

\section{Model Description}

\subsection{Ocean Primitive Equations}

The horizontal momentum balance for a hydrostatic Boussinesq fluid on a rotating sphere is

$$
\frac{d \vec{v}_{o}}{d t}+f\left(\vec{k} \times \vec{v}_{o}\right)=-\frac{1}{\rho_{w}}\left[\vec{\nabla}_{H}\left(p+\rho_{w} g \zeta\right)\right]+\vec{F}_{H}+\vec{F}_{V}
$$

where $\vec{v}_{o}=\left(u_{o}, v_{o}\right)$ is the oceanic horizontal velocity vector on the orthogonal co-

ordinates, $\mathrm{t}$ is the time, $f$ is the Coriolis parameter, $\vec{k}$ is a unit vector normal to the earth's centre, $\rho_{w}$ is a constant reference density, $\vec{\nabla}_{H}$ is the horizontal gradient 
operator, $p$ is the internal pressure, $\mathrm{g}$ is the acceleration due to gravity and $\zeta$ is the sea surface elevation. The total derivative is given by $\frac{d}{d t}=\frac{\partial}{\partial t}+\vec{v}_{o} \cdot \vec{\nabla}_{H}+w_{o} \cdot \frac{\partial}{\partial z}$ where $w_{o}$ is the vertical component of ocean velocity and $\frac{\partial}{\partial z}$ is the vertical partial derivative. $\vec{F}_{H}$ and $\vec{F}_{V}$ are parameterisations of horizontal and vertical eddy viscosity, respectively.

Diagnostic treatment of pressure and density is used to close the momentum balance. Density $\rho$ is taken to be a function of model pressure, temperature and salinity according to the equation of state polynomial defined by the Joint Panel on Oceanographic Tables and Standards (UNESCO, 1983). Potential temperatures are converted to in situ temperatures for the density calculation. The pressure is calculated using the hydrostatic equation.

$$
\frac{\partial p}{\partial z}=-g \rho
$$

Forward integration of the ocean model surface elevation is based on a linearised kinematic boundary condition stating that the time rate of change of surface elevation is equal to the vertical component of oceanic velocity at the surface.

$$
\frac{\partial \zeta}{\partial t}=\left.w_{o}\right|_{z=\zeta}
$$

The vertical velocity is calculated from the horizontal velocity field using the incompressibility condition.

$$
\frac{\partial w_{o}}{\partial z}=-\vec{\nabla}_{H} \cdot \vec{v}_{o}
$$

Integrating over the entire depth gives the vertical velocity at the sea surface.

$$
\left.w_{o}\right|_{z=\zeta}=-\vec{\nabla}_{H} \cdot \int_{-H}^{\zeta} \vec{v}_{o} d z
$$

Potential temperature $\theta$ and salinity $S$ obey the advection-diffusion equations

$$
\begin{aligned}
\frac{d \theta}{d t} & =\vec{\nabla}_{H} \cdot\left(\mathbf{K} \vec{\nabla}_{H} \theta\right) \\
\frac{d S}{d t} & =\vec{\nabla}_{H} \cdot\left(\mathbf{K} \vec{\nabla}_{H} S\right)
\end{aligned}
$$

where the tensor $\mathbf{K}$ is a subgridscale parameterisation of horizontal/isoneutral and vertical/dianeutral diffusion.

\subsection{Ocean Subgridscale Parameterisations}

The coarse horizontal and vertical resolution of OGCMs necessitates the use of subgridscale parameterisations. The MPI-OM-1 model currently has formulations for BBL slope transport, horizontal and vertical viscosity, vertical and isopycnal diffusivity, eddy-induced mixing, and convection, as described below. With respect to the many parameter choices necessary for inclusion of subgridscale processes in the MPI-OM-1 model (and OGCMs more generally), we note the myriad sensitive interactions that such choices have on each other. Since computational constraints do not currently permit a full spanning of parameter space the parameter choices used in the present version of MPI-OM-1 are a necessary blend of those gained via 
past experience with the HOPE model, those available from the bandwidth of literature values, and those that were tuned (in a sometimes ad hoc manner traditionally referred to as the art of numerical modelling) to give iteratively improved results as part of the model development process. The latter is relevant to, for example, our choices of friction, diffusion, convection and wind mixing parameters.

The thermohaline circulation of the world's ocean is maintained by the sinking of dense water masses in high latitudes. In most cases these water masses form in marginal seas or on shelves and slide down the continental slopes. One particular phenomenon is the 'overflow', where dense near-bottom waters cross sills between ocean basins (e.g. Price and Baringer, 1994). This process is not well resolved in coarse-resolution z-coordinate ocean models owing to a lack of a BBL. In such models the dense water passing over a sill is advected horizontally and placed above lighter water. The resulting convection (parameterised as strong mixing or intensified diffusion) leads to an overestimation of the mixing between the overflow and the ambient water. To overcome this problem Beckmann and Döscher (1997) developed a BBL parameterisation where the horizontal flow is redirected as if it flowed along the bottom. This approach to the BBL problem can be avoided by the use of $\sigma$-coordinate models (e.g. Ezer and Mellor, 1997), which are been compared to both isopycnal and z-coordinate models in the Dynamics of Overflow, Mixing and Entrainment (DOME) Project. Advantages and disadvantages of the various vertical coordinate systems are discussed by the DYNAMO Group (1997) or on the DOME webpage (www.rsmas.miami.edu/personal/tamay/DOME/dome.html).

In the HOPE model a relatively simple slope convection scheme was introduced by Legutke and Maier-Reimer (2001). In the Legutke and Maier-Reimer scheme the slope convection was considered to be a directional diffusive transport whereby an exchange of tracer occurs between the bottom cells of two adjacent horizontally discretised water columns. The BBL scheme newly introduced into MPI-OM-1 is schematically represented in Fig. 1 which shows the BBL transport $\operatorname{Tr}_{B B L}$ from a source cell to a target cell. The implementation is similar to that of Beckmann and Döscher (1997) with two notable exceptions. Firstly, the BBL thickness $H_{B B L}$ may be less than the model layer thickness $\Delta z_{s}$ of the source cell. That is,

$$
H_{B B L}=\min \left(\Delta z_{s}, B B L_{\max }\right)
$$

where $\mathrm{BBL}_{\max }$ is a prescribed maximum thickness. The motivation is to limit the BBL transport in coarse vertical resolution ocean models where the deeper grid cells can be of order $1 \mathrm{~km}$ thickness. Secondly, as suggested by Campin and Goosse (1999) the BBL transport is redirected to a level of neutral buoyancy rather than to the bottom cell of a horizontally adjacent water column. For a source cell having density $\rho_{s}$ at model level $\mathrm{k}_{s}$, the target cell level $\mathrm{k}_{t}$ is chosen by the following condition.

$$
k_{t}=\left\{\begin{array}{ll}
k_{\rho} & \text { if } \quad \rho_{t} \leq \rho_{s} \\
k_{b o t} & \text { if } \quad \rho_{b o t} \leq \rho_{s}
\end{array} \text { and } \quad \rho_{t+1}>\rho_{s}\right.
$$

Here, the subscript bot denotes the deepest wet model layer in a target column. The neutral buoyancy approach is particularly useful in regions where coarse horizontal resolution does not allow for a gradual descent on a staircase-like slope. The resultant BBL transport is given by

$$
\operatorname{Tr}_{B B L}=u_{s} \Delta x, y H_{B B L}
$$

where $u_{s}$ represents the meridional (parallel) velocity in the model level $\mathrm{k}_{s}$, and $\Delta x, y$ represents the parallel (meridional) source cell width. The remaining advective 


$$
\operatorname{Tr}=u_{s} \Delta x, y\left(\Delta z_{s}-H_{B B L}\right)
$$

and is purely horizontal. Although not used in this study, MPI-OM-1 also includes an improved version of the BBL scheme where $H_{B B L}$ is calculated locally depending on the stratification and friction velocity using the formulation of Killworth and Edwards (1999).

The horizontal and vertical eddy viscosity are treated separately. Horizontal eddy viscosity $\vec{F}_{H}$ is parameterised using a scale-dependent biharmonic formulation

$$
\vec{F}_{H}=-\vec{\nabla}_{H} \cdot\left(B_{H} \vec{\nabla}_{H} \Delta_{H} \vec{v}_{o}\right)
$$

where $B_{H}$ is a coefficient proportional to the fourth power of the grid spacing.

Vertical eddy viscosity $\vec{F}_{V}$ is parameterised as

$$
\vec{F}_{V}=\frac{\partial}{\partial z}\left(A_{V} \frac{\partial}{\partial z} \vec{v}_{o}\right) .
$$

The eddy coefficient $A_{V}$ is partially relaxed to the value at the previous time step by use of a time filter to avoid $2 \Delta t$ oscillation. Using $n$ and $\Lambda_{V}$ to denote the time increment and relaxation coefficient gives:

$$
A_{V}^{n}=\left(1-\Lambda_{V}\right) A_{V}^{n-1}+\Lambda_{V}\left(A_{V O}\left(1+C_{R A} R_{i}\right)^{-2}+A_{w}+A_{b}\right) .
$$

The time linear relaxation coefficient $\Lambda_{V}$ is set to 0.6 in accordance with past experience. Following Pacanowski and Philander (PP; 1981) the Richardson number $R_{i}$ dependent mixing term includes constant coefficients $A_{V O}$ and $C_{R A}$. A small constant background viscosity representing mixing by internal wave breaking is denoted by $A_{b}$. The PP scheme in its classical form underestimates turbulent mixing close to the surface. Therefore an additional parameterisation for the wind induced stirring $A_{w}$ is included. The near surface wind mixing is proportional to the cube of the local ten metre wind speed $V_{10 m}$, and is reduced in proportion to the fractional sea ice cover $I$. It decays exponentially with depth and depends on the local static stability $\delta_{z} \rho$.

$$
\begin{aligned}
& A_{w}(1)=(1-I) W_{T} V_{10 m}^{3} \\
& A_{w}(k)=A_{w}(k-1) \frac{\frac{\lambda}{\Delta z}}{\frac{\lambda}{\Delta z}+\delta_{z} \rho} e^{\frac{\Delta z}{z_{0}}}
\end{aligned}
$$

where $\mathrm{k}=2,3, \ldots, k_{b o t}$ is the vertical level and $\Delta z$ is the level thickness; $\lambda, z_{0}$, and $W_{T}$ are adjustable parameters which were tuned for optimal mixed layer depths.

Tracer diffusion in Eqns 6 and 7 is represented in two optional ways. The diffusion tensor $\mathbf{K}$ can be chosen either to represent: a) standard horizontal/vertical diffusion

$$
\mathbf{K}=D_{H}\left[\begin{array}{lll}
1 & 0 & 0 \\
0 & 1 & 0 \\
0 & 0 & \epsilon
\end{array}\right]
$$

with $\epsilon=\frac{D_{V}}{D_{H}} ;$ or b) isoneutral/dianeutral diffusion

$$
\mathbf{K}=D_{H}\left[\begin{array}{ccc}
1 & 0 & S_{x} \\
0 & 1 & S_{y} \\
S_{x} & S_{y} & \epsilon+S_{d i f}^{2}
\end{array}\right]
$$


with $\epsilon=\frac{D_{V}}{D_{H}}$ and $S_{d i f}=\left(S_{x}, S_{y}, 0\right)=\left(\frac{-\delta_{x} \rho}{\delta_{z} \rho}, \frac{-\delta_{y} \rho}{\delta_{z} \rho}, 0\right)$.

The transformation follows Redi (1982) with the small slope approximation by Gent et al. (1995). The scheme is numerically implemented following Griffies (1998). All the experiments presented in this article utilise isoneutral/dianeutral diffusion.

The effect of tracer mixing by advection with the unresolved mesoscale eddies is parameterised after Gent et al. (1995).

The vertical eddy diffusivity coefficient $D_{V}$ is treated similarly to Eqn 14, except for the cubic dependence on the shear instability-dependent (Richardson number) term:

$$
D_{V}^{n}=\left(1-\Lambda_{D}\right) D_{V}^{n-1}+\Lambda_{D}\left(D_{V O}\left(1+C_{R D} R_{i}\right)^{-3}+D_{w}+D_{b}\right) .
$$

As with the vertical viscosity, $D_{V O}, C_{R D}$ and the small background term $D_{b}$ are constant. The wind-induced term $D_{w}$ is treated in the same manner as for viscosity.

There are three choices for parameterisation of convection currently available in the MPI-OM-1 model. Convective adjustment follows Bryan (1969). Traditionally this technique involved the full mixing of vertically adjacent grid cells in the presence of static instability. The MPI-OM-1 formulation is similar but only mixes the upper grid cell with an equivalent thickness of the lower grid cell. This approach aims to increase the penetrative depth of convection. Alternatively MPI-OM-1 allows for the use of a much more physically based parameterisation based on the penetrative plume convection scheme of Paluszkiewicz and Romea (1997). Plume convection was found to significantly improve the deep water characteristics and the simulation of Southern Ocean sea ice in the HOPE model (Kim and Stössel, 2001). However, the penetrative plume convection scheme is computationally quite expensive and is not used in the simulations described in this paper. The third scheme, and also the one used in this study, is the parameterisation of convection by greatly enhanced vertical diffusion in the presence of static instability (e.g. Marotzke, 1991; Klinger at al., 1996). Such an approach avoids the excessive intermediate mixing associated with the traditional adjustment scheme by introducing a timescale associated with the choice of (constant) convective-diffusion coefficient.

\subsection{Sea Ice Dynamics and Thermodynamics}

Sea ice motion is determined by a two-dimensional momentum balance equation.

$$
\frac{d \vec{v}_{i}}{d t}+f\left(\vec{k} \times \vec{v}_{i}\right)=-g \vec{\nabla} \zeta+\frac{\overrightarrow{\tau_{a}}}{\rho_{i} h_{i}}+\frac{\vec{\tau}_{o}}{\rho_{i} h_{i}}+\vec{\nabla} \cdot \sigma_{m n}
$$

Here $f, \vec{k}, \zeta, g$, and $t$ are as in Eqn 1. Sea ice of thickness $h_{i}$ and density $\rho_{i}$ has a velocity $\vec{v}_{i}$ which responds to wind stress $\overrightarrow{\tau_{a}}$, ocean current stress $\overrightarrow{\tau_{o}}$, and an internal ice stress represented by the two dimensional stress tensor $\sigma_{m n}$. It is noted that inclusion of the nonlinear (advective) terms in Eqn 20 considerably reduces the model timestep. For the standard MPI-OM-1 setup considered in Section 5 the timesteps with and without the advective terms are 15 and 36 minutes respectively. To reduce computational expenditure the nonlinear terms were therefore neglected in the simulations considered here. In Eqn. 20 the stress terms are in units of $\mathrm{N} \mathrm{m}^{-2}$. From above $\overrightarrow{\tau_{a}}$ is taken as prescribed forcing, while from below $\overrightarrow{\tau_{o}}$ is parameterised as

$$
\overrightarrow{\tau_{o}}=\rho_{w} C_{W}\left|\vec{v}_{1}-\vec{v}_{i}\right|\left(\vec{v}_{1}-\vec{v}_{i}\right)
$$


where $\vec{v}_{1}$ is the upper ocean layer velocity and the constant coefficient of bulk momentum exchange is given by $C_{W}$. Currently no turning angles are employed for the atmosphere and ocean/ice stress terms.

The choice of sea ice rheology $\sigma_{m n}$ determines the way in which ice flows, cracks, ridges, rafts and deforms. Following Hibler (1979) internal sea ice stress is modelled in analogy to a nonlinear viscous compressible fluid obeying the constitutive law

$$
\sigma_{m n}=2 \eta \dot{\epsilon}_{m n}+\left\{(\xi-\eta)\left(\dot{\epsilon}_{11}+\dot{\epsilon}_{22}\right)-\frac{P_{i}}{2}\right\} \delta_{m n}
$$

where $\dot{\epsilon}_{m n}$ is the strain rate tensor and $\delta_{m n}(m, n \in\{1,2\})$ is the Kronecker delta. The internal sea ice pressure $P_{i}$ is a function of sea ice thickness $h_{i}$ and subgridscale areal fractional sea ice compactness

$$
P_{i}=P^{*} h_{i} e^{-C(1-I)}
$$

where $P^{*}$ and $C$ are empirically derived constants. The pressure is related to the nonlinear bulk $\xi$ and shear $\eta$ viscosities according to:

$$
\begin{gathered}
\xi=\frac{P_{i}}{2 \Delta} ; \eta=\frac{\xi}{e^{2}} \\
\Delta=\left[\left(\dot{\epsilon}_{11}^{2}+\dot{\epsilon}_{22}^{2}\right)\left(1+\frac{1}{e^{2}}\right)+4 \frac{\dot{\epsilon}_{12}^{2}}{e^{2}}+2 \dot{\epsilon}_{11} \dot{\epsilon}_{22}\left(1-\frac{1}{e^{2}}\right)\right]^{\frac{1}{2}}
\end{gathered}
$$

Here $e$ is the ratio of the lengths of the principal axes of the yield ellipse (these correspond to the principal components in stress space, i.e. $\sigma_{11}$ and $\sigma_{22}$ from Eqn 22). The yield ellipse discriminates between linear-viscous (internal) and plastic (boundary) points in stress space, while exterior points cannot be reached. Numerical problems arise when the strain rates are small. Then the $\Delta$ in Eqn 25 approaches zero, and the viscosities in Eqn 24 approach infinity. Following Hibler (1979), the problem is avoided by choosing the viscosities to be a maximum of their function value given in Eqn 24, and an empirically chosen maximum value corresponding to the function value when $\Delta=\Delta_{\min }=2.0 \times 10^{-9} \mathrm{~s}^{-1}$.

Thermodynamics of sea ice involves the determination of the local growth or melt rate at the base of the sea ice and the local melt rate at the surface. To allow for the prognostic treatment of the subgridscale fractional sea ice cover the surface heat balance is solved separately for the ice covered and ice free areas. That is, the net atmospheric heat flux $Q_{a}$ is weighted according to the open water heat flux $Q_{w}$ and heat flux over sea ice (or sea ice and snow) $Q_{i}$.

$$
Q_{a}=(1-I) Q_{w}+I Q_{i}
$$

A thermodynamic equilibrium is sought at the interface between the atmosphere and the sea ice/snow layer. An initial solution $T_{s r f}^{*}$ is found for the sea ice/snow layer surface temperature $T_{\text {srf }}$ from the energy balance equation

$$
Q_{i}+Q_{\text {cond }}=0
$$

The conductive heat flux $Q_{\text {cond }}$ within the sea ice/snow layer is assumed to be directly proportional to the temperature gradient across the sea ice/snow layer and inversely proportional to the thickness of that layer (i.e. the so-called zero-layer formulation of Semtner, 1976).

$$
Q_{\text {cond }}=k_{i} \frac{\left(T_{\text {freeze }}-T_{\text {srf }}\right)}{8}
$$


Here $k_{i}$ is the thermal conductivity of sea ice, $T_{\text {freeze }}$ the freezing temperature of sea water and $\tilde{h}_{i}$ the effective thermodynamic sea ice thickness of the sea ice/snow layer. This effective thickness is defined to be

$$
\tilde{h}_{i}=\frac{1}{I}\left(h_{i}+h_{s} \frac{k_{i}}{k_{s}}\right)
$$

where $h_{s}$ is the snow layer thickness and $k_{s}$ is the thermal conductivity of the snow. The ratio of the thermal conductivity of sea ice with respect to that of snow is approximately 7 . This means that snow is seven times more effective as an insulator against oceanic heat loss to the atmosphere than sea ice. Hence, even a relatively thin snow cover will result in a much increased effective sea ice thickness. Atmospheric precipitation is converted to snow fall when $T_{a}$ is below $0^{\circ} \mathrm{C}$. Snow loading on the sea ice may result in the submerging of the sea ice/snow interface. In such cases the thickness of the snow draft is converted to sea ice. Since the heat of fusion of snow is slightly greater than the heat of fusion of sea ice this process results in a net heat gain to the sea ice/snow layer. To close the heat balance of the conversion process a small additional amount of snow is also melted.

When the initial solution $T_{s r f}^{*}$ in Eqn 28 is greater than $0^{\circ} \mathrm{C}$ the left-hand side of Eqn 27 is recalculated with $T_{s r f}$ replaced by $0^{\circ} \mathrm{C}$ and the resultant energy is used to melt snow and then sea ice from above. In the case where the entire sea ice/snow layer is melted from above any remaining heat is added to $Q_{w}$ in Eqn 26.

To complete the sea ice thermodynamic evolution a heat balance equation must also be applied at the ocean/sea ice and ocean/atmosphere interfaces. The balance equation takes the form

$$
\rho_{w} c_{w} \Delta z_{1}^{\prime} \frac{\partial \hat{\theta}_{1}}{\partial t}=(1-I) Q_{w}+I\left(Q_{c o n d}-h_{i} \rho_{i} L_{i}\right)
$$

and is solved for an interim upper layer oceanic temperature $\hat{\theta}_{1}$. Here $c_{w}$ is the specific heat capacity of sea water, $L_{i}$ is the latent heat of fusion of sea ice and $\Delta z_{1}^{\prime}$ is the thickness of the upper ocean layer, given by

$$
\Delta z_{1}^{\prime}=\Delta z_{1}+\zeta-h_{d r a f t}
$$

where $\Delta z_{1}$ is the defined constant thickness of the ocean model's upper layer. The draft of the sea ice/snow layer $h_{\text {draft }}$ is given by

$$
h_{d r a f t}=\frac{1}{\rho_{w}}\left(\rho_{i} h_{i}+\rho_{s} h_{s}\right) .
$$

where $\rho_{i}$ and $\rho_{s}$ are the densities of the sea ice and snow layers respectively. Note that the treatment of a sea ice draft is purely for thermodynamic considerations, and that the ocean momentum balance is not effected. The embedding of sea ice into the upper ocean layer, as opposed to allowing sea ice to exist in multiple ocean layers, is for computational convenience. However, such treatment introduces an upperbound to the sea thickness. In MPI-OM-1 the sea ice draft is not allowed to remain above a local maximum sea ice draft specified as

$$
h_{\text {maxdraft }}=0.7\left(\Delta z_{1}+\zeta\right) .
$$

Any additional sea ice draft is converted to water in a salt (but currently not heat) conserving way. It is noted that this critical sea ice thickness is never reached in 
the 51 years considered from the simulations using the standard grid of MPI-OM-1 in Section 5. For the sea ice undersurface to be in thermal equilibrium with the upper ocean it is required that $T_{\text {melt }} \leq \theta_{1} \leq T_{\text {freeze }}$. To maintain this inequality sea ice/snow is melted when the solution for $\hat{\theta}_{1}$ from Eqn 30 is above $T_{\text {melt }}$ and new sea ice is formed when $\hat{\theta}_{1}$ is below $T_{\text {freeze }}$. For the purposes of this study the effect of salinity on the freezing and melting temperatures is ignored and constant values of $T_{\text {freeze }}$ and $T_{\text {melt }}$ are used. The model upper layer ocean temperature $\theta_{1}$ is only allowed to rise above $T_{\text {melt }}$ when all of the sea ice/snow layer has been melted within a grid cell. Then the new upper ocean temperature $\theta_{1}$ and the change in sea ice thickness $\Delta h_{i}$ are given by

$$
\begin{gathered}
\theta_{1}=\hat{\theta}_{1}-\min \left\{\frac{h_{i} \rho_{i} L_{f}}{\rho_{w} c_{w} \Delta z_{1}^{\prime}}, \hat{\theta}_{1}-T_{\text {freeze }}\right\} \\
\Delta h_{i}=\max \left\{\left(T_{\text {freeze }}-\hat{\theta}_{1}\right) \frac{\rho_{w} c_{w} \Delta z_{1}^{\prime}}{\rho_{i} L_{f}}, 0\right\} .
\end{gathered}
$$

For freezing conditions, the upper ocean temperature and the sea ice thickness change are

$$
\begin{gathered}
\theta_{1}=T_{\text {freeze }} \\
\Delta h_{i}=\frac{\hat{\theta}_{1}-T_{\text {freeze }}}{\rho_{i} L_{f}} \rho_{w} c_{w} \Delta z_{1}^{\prime} .
\end{gathered}
$$

Subgridscale thermodynamic processes of sea ice growth and melt are assumed to effect the sea ice compactness within a grid cell in the following ways. When freezing occurs over open water areas the sea ice compactness increases (i.e. leads concentration decreases) at a rate given by

$$
\Delta I^{\text {thin }}=\max \left\{\frac{\Delta h_{i}^{\text {thin }}(1-I)}{h_{o} \Delta t}, 0\right\}
$$

where $\Delta t$ is the model timestep, $\Delta h_{i}^{\text {thin }}=\Delta t Q_{w} /\left(\rho_{i} L_{f}\right)$ is the thickness of new sea ice formed and $h_{o}$ is an arbitrary demarcation thickness (taken to be $0.5 \mathrm{~m}$ following Hibler, 1979). When melting of thick sea ice occurs the sea ice compactness decreases (i.e. leads concentration increases) at a rate given by

$$
\Delta I^{\text {thick }}=\min \left\{\frac{\Delta h_{i}^{\text {thick }} I}{2 h_{i} \Delta t}, 0\right\}
$$

where $\Delta h_{i}^{\text {thick }}$ is the change in sea ice thickness due to the melting. This formulation is based on the assumption that sea ice thickness within a grid cell has a uniform distribution between 0 and $2 h_{i}$. The change in compactness of sea ice due to thermodynamic lead opening and closing is then calculated as the sum of both these terms.

$$
\frac{\partial I}{\partial t}=\Delta I^{t h i n}+\Delta I^{t h i c k}
$$

Completion of the sea ice thermohaline coupling to the ocean model requires consideration of salt and fresh water exchanges during sea ice growth and melt. Sea ice is assumed to have a constant salinity independent of it's age and denoted by $S_{\text {ice }}$. While multi-year Arctic sea ice has a salinity of around 3 psu, thinner ice in both hemispheres has a much higher salinity (Cox and Weeks, 1974; Eicken, 1992). For the simulations in Section 5 an intermediate value of 5 psu representing this global 
diversity has been chosen. The ocean model's upper layer salinity $\mathrm{S}_{1}$ is changed by an amount $\Delta S$ due to the surface fresh water flux (modified by snow fall which accumulates on top of the sea ice) and due to sea ice growth or melt, according to:

$$
\left(S_{1}+\Delta S\right) \Delta z^{\text {old }}+\frac{\rho_{i} h_{i}^{\text {old }}}{\rho_{w}} S_{i c e}=S_{1} \Delta z^{\text {lnew }}+\frac{\rho_{i} h_{i}^{\text {new }}}{\rho_{w}} S_{\text {ice }}
$$

Here $\Delta z^{\text {lold }}$ is the upper ocean layer thickness accounting for sea surface elevation and sea ice draft as in Eqn 31, and also for the atmospheric precipitation minus evaporation. $\Delta z^{\text {Inew }}$ is $\Delta z^{\text {lold }}$ modified by the new sea ice draft due to melt or growth, and $h_{i}^{\text {new }}-h_{i}^{\text {old }}$ is the amount of sea ice growth (if positive) or melt (if negative).

\section{$2.4 \quad$ Timestepping}

The timestepping proceeds by the method of operator splitting or fractional steps as described by e.g. Press et al. (1988). That is, prognostic variables are updated successively in several subroutines. Prescribed forcing is read in at the start of each timestep after which the sea ice dynamics equations are solved by means of functional iteration with under relaxation. Then the sea ice thermodynamics are implemented. The ocean momentum equation is first solved partially for the friction terms and then the advection terms. This results in a partially updated momentum equation which is decomposed into baroclinic and barotropic subsystems. These are solved separately as described below. As in HOPE the prognostic equation for the free surface is solved implicitly (see Wolff et al., 1997, for details), which allows for the model's barotropic timestep to equal the baroclinic timestep.

Denoting the internal baroclinic pressure divided by reference density as $p^{\prime}$, and the three dimensional baroclinic velocities as $\left(u^{\prime}, v^{\prime}, w^{\prime}\right)$, the partially updated baroclinic momentum equations can be expressed by

$$
\begin{aligned}
& \frac{\partial u^{\prime}}{\partial t}-f v^{\prime}=\frac{1}{H} \int_{-H}^{\zeta} \frac{\partial p^{\prime}}{\partial x} d z-\frac{\partial p^{\prime}}{\partial x} \\
& \frac{\partial v^{\prime}}{\partial t}+f u^{\prime}=\frac{1}{H} \int_{-H}^{\zeta} \frac{\partial p^{\prime}}{\partial y} d z-\frac{\partial p^{\prime}}{\partial y}
\end{aligned}
$$

where $x, y, z$ and $t$ indicate the curvilinear parallel, curvilinear meridional, vertical and temporal dimensions respectively. The local depth is given by $H, \zeta$ is the sea surface displacement from the z-coordinate uppermost surface, and $f$ is the Coriolis parameter. Assuming only disturbances of small amplitude (linearisation) allows the vertical density advection to be expressed as $\frac{\partial \rho}{\partial t}=-w \frac{\partial \rho}{\partial z}$. This can be combined with the time derivative of the hydrostatic approximation $\left(\frac{\partial \rho^{2}}{\partial z \partial t}=\frac{-g}{\rho_{0}} \frac{\partial \rho}{\partial t}\right)$ to give an equation for the time evolution of the linearised internal baroclinic pressure

$$
\frac{\partial^{2} p^{\prime}}{\partial z \partial t}=\frac{w g}{\rho_{0}} \frac{\partial \rho}{\partial z}
$$

Then the baroclinic subsystem is closed with the baroclinic continuity equation.

$$
\frac{\partial u^{\prime}}{\partial x}+\frac{\partial v^{\prime}}{\partial y}+\frac{\partial w^{\prime}}{\partial z}=0
$$


Introducing the superscripts $n$ and $n+1$ to denote old and new time levels respectively, the time discretisation of the partially updated linearised baroclinic subsystem can then be written as

$$
\begin{aligned}
& u^{\prime^{n+1}}-u^{\prime^{n}}=\alpha \Delta t\left(f v^{\prime^{n+1}}+\frac{1}{H} \int_{-H}^{\zeta} p_{x}^{\prime^{n+1}} d z-p_{x}^{\prime^{n+1}}\right) \\
& +(1-\alpha) \Delta t\left(f v^{\prime^{n}}+\frac{1}{H} \int_{-H}^{\zeta} p_{x}^{\prime^{n}} d z-p_{x}^{\prime^{n}}\right) \\
& v^{n^{n+1}}-v^{\prime^{n}}=\alpha \Delta t\left(-f u^{\prime^{n+1}}+\frac{1}{H} \int_{-H}^{\zeta} p_{y}^{\prime^{n+1}} d z-p_{y}^{\prime^{n+1}}\right) \\
& +(1-\alpha) \Delta t\left(-f u^{\prime^{n}}+\frac{1}{H} \int_{-H}^{\zeta} p_{y}^{\prime n} d z-p_{y}^{n^{n}}\right) \\
& p_{z}^{\prime^{n+1}}-p_{z}^{\prime^{n}}=\frac{g}{\rho_{0}} \Delta t \rho_{z}\left(\beta w^{\prime^{n+1}}+(1-\beta) w^{\prime^{n}}\right)
\end{aligned}
$$

Here $\Delta t$ is the model's timestep, and $0 \leq \alpha, \beta \leq 1$ are stability coefficients partially weighting the new velocities to the old velocities. For stability reasons it is required that $\alpha \geq 1-\alpha$ and $\beta \geq 1-\beta$. In the semi-implicit case where $\alpha=\beta=\frac{1}{2}$ the system is neutrally stable, but similar to the familiar leapfrog-scheme this tends to produce a computational mode with $2 \Delta t$ oscillations. These are suppressed by the choice $\alpha=0.55$ and $\beta=0.5$. The system is solved iteratively with the old baroclinic velocities used as a first guess.

For the partially updated barotropic subsystem, the momentum equations are

$$
\begin{aligned}
& \frac{\partial U}{\partial t}-f V+g H \frac{\partial \zeta}{\partial x}+\int_{-H}^{\zeta} \frac{\partial}{\partial x} p^{\prime} d z=0 \\
& \frac{\partial V}{\partial t}+f U+g H \frac{\partial \zeta}{\partial y}+\int_{-H}^{\zeta} \frac{\partial}{\partial y} p^{\prime} d z=0
\end{aligned}
$$

where $U$ and $V$ are the partially updated barotropic velocities on the model's curvilinear grid. The barotropic subsystem is closed with a continuity equation accounting for the time derivative of the sea level $\zeta$

$$
\frac{\partial \zeta}{\partial t}+\frac{\partial U}{\partial x}+\frac{\partial V}{\partial y}=Q_{\zeta}
$$

where the forcing term $Q_{\zeta}$ represents the surface freshwater flux (see Eqn 63 below). The sea level is partially updated according to $Q_{\zeta}$ before the baroclinic subsystem is solved and so is ignored in the following time discretisation.

Denoting the partially updated sea level by $\zeta^{\prime}$, the discretised partially updated barotropic subsystem can then be written as

$$
\begin{gathered}
U^{n+1}-U^{n}-f \Delta t\left(\alpha V^{n+1}+(1-\alpha) V^{n}\right) \\
+g H \Delta t\left(\alpha \zeta_{x}^{n+1}+(1-\alpha) \zeta_{x}^{\prime n}\right)+\Delta t \int_{-H}^{\zeta} p_{x}^{\prime n+1} d z=0 \\
V^{n+1}-V^{n}+f \Delta t\left(\alpha U^{n+1}+(1-\alpha) U^{n}\right) \\
+g H \Delta t\left(\alpha \zeta_{y}^{n+1}+(1-\alpha) \zeta_{y}^{\prime n}\right)+\Delta t \int_{-H}^{\zeta} p_{y}^{\prime n+1} d z=0 \\
\zeta^{\prime^{n+1}}-\zeta^{\prime n}+\Delta t\left(\beta\left(U_{x}^{n+1}+V_{y}^{n+1}\right)+(1-\beta)\left(U_{x}^{n}+V_{y}^{n}\right)\right)=0
\end{gathered}
$$


where the partial temporal relaxation weights $\alpha$ and $\beta$ are the same as for the baroclinic subsystem. The set of equations 52,53 and 54 is rearranged into matrix form and solved by Gaussian elimination with back substitution. Alternatively, when the model dimensions exceed the availability of core computing memory, the matrix can be solved iteratively using successive over-relaxation. For a discussion of how the implicit free surface approach of MPI-OM-1 compares with explicit treatment of the free surface the reader is referred to Griffies et al. (2000).

Momentum advection of tracers is by a mixed scheme that employs a weighted average of both central-difference and upstream methods. The weights are chosen according to the ratio of the second spatial derivative over the first spatial derivative of the advected quantity. When the magnitude of this ratio is less than 1 the weights favour usage of central-differencing, and when greater than 1 the upstream scheme is preferred. The idea is to incorporate the benefit of positive-definiteness of the upstream scheme (and thus limit numerically spurious tracer sources and sinks), while avoiding large implicit numerical diffusion in regions where strong gradients exist in the tracer field.

\section{Model Grid}

Horizontal discretisation of the MPI-OM-1 model is on an Arakawa C-grid (Arakawa and Lamb, 1977). Vertical discretisation is on a so called ' $\mathrm{z}$-coordinate' system (differentiating from pressure or density coordinate systems). The vertical discretisation is the same as used in the HOPE model (Wolff et al., 1997), which includes partial vertical grid cells, i.e. at each point in the horizontal grid the deepest wet cell has a uniform thickness that is adjusted to resolve the discretised bathymetry. The surface layer thickness is also adjusted to account for the sea surface elevation and the sea ice/snow draft where appropriate.

The MPI-OM-1 model uses a bipolar orthogonal spherical coordinate system. If the poles are antipodes (diametrically opposed) then the coordinate system is reduced to a rotated spherical grid. Otherwise, orthogonal meridians and parallels are constructed according to the choice of zonal and meridional resolution and are used to define the spatial mesh. Although it may be desirable to maintain 'quadrature' of the grid (i.e. within each grid cell the local zonal and meridional grid distances are equal), it is by no means a necessary condition. Two advantages can be achieved by assignment of a radius to the poles. Firstly, land points can be removed from the computational matrix. Secondly, by choosing non-equal pole radii horizontal resolution can be concentrated about the pole of smaller radius for regional studies. Implementation of the curvilinear grid is relatively straightforward but does require some additional computational expense. In terms of memory many additional arrays must be added for storage of all terms related to horizontal metrics between both scalar and vector neighbouring pairs. The processing time is therefore extended for all operations including horizontal metrics that could otherwise be factored on a regular grid. This condition is omnipresent throughout the model code with the exception of purely vertical operations such as convection.

The standard MPIfM horizontal ocean grid used for climate studies has traditionally been at a spatial resolution approximating spectral truncation T42 with additional equatorial meridional grid refinement (e.g. HOPE, Legutke and Voss, 1999; OPYC, Roeckner at al., 1999). The equatorial refinement results in a merid- 
ional resolution of $0.5^{\circ}$ between $10^{\circ} \mathrm{N}$ and $10^{\circ} \mathrm{S}$. For applications with the MPI-OM-1 model, advantage has been taken of the orthogonal curvilinear coordinates to produce the modified grid as shown in Fig. 2. Both the north and south poles have a radius of $148 \mathrm{~km}$ and are located on $30^{\circ} \mathrm{W}$ at $80^{\circ} \mathrm{N}$ and $80^{\circ} \mathrm{S}$ respectively (i.e. over Greenland and inland of the Weddell Sea). This arrangement gives highest resolution in the main sinking regions associated with the thermohaline circulation (THC), and has the advantage that by symmetry the equator lies along one of the model's orthogonal parallels.

The horizontal grid described above is by no means the only one in use at the MPIfM. Some of the examples that are currently in use for more regionally focused studies are shown in Fig. 3. There can be seen applications to the Greenland, Irminger and Norwegian Seas (GIN), to the Indonesian Throughflow region (BANDA), and to the Mertz Glacier coastal polynya system of East Antarctica (MERTZ). In each case the poles are chosen so as to give relatively high resolution in the region of interest, while maintaining a global model domain that avoids the non-trivial problems experienced with both open and closed boundary models. However, it should be noted that this approach has the disadvantage of globally constraining the model timestep to one small enough to be appropriate for the highest resolution region. Such a limitation could be avoided by use of nested models, although such models have problems of there own (e.g. Fox and Maskell, 1995).

\section{Atmospheric Surface Forcing}

Simulation with the MPI-OM-1 model requires the specification of heat, freshwater and momentum fluxes at the air/sea interface. In this study use is made of a climatological forcing dataset with daily temporal resolution and atmospheric synoptic scale variability. The forcing data is taken from the German Ocean Model Intercomparison Project (OMIP) climatology, and hereafter is called the OMIP-forcing. OMIP was a collaboration between MPIfM, the German Climate Computing Center (DKRZ) and the Alfred Wegener Institute for Polar and Marine Research. The OMIP project (www.mpimet.mpg.de/Depts/Klima/natcli/omip/omip_report.html) compared the mean state of the global circulation of HOPE with that of the Modular Ocean Model (MOM2; Pacanowski, 1995). Considerable emphasis was also placed on the generation of a surface heat and freshwater flux climatology. The OMIPforcing was derived from the ECMWF Re-Analysis (ERA; Gibson et al., 1997) 15 year dataset and is documented by Röske (2001).

Three criteria were used for the design of the OMIP-forcing: that the forcing be global; that the forcing resolves timescales associated with weather systems; and that the horizontal resolution of the forcing be somewhat finer than that commonly used in OGCMs. The forcing was constructed by Gaussian filtering of the ERA data to produce a low-frequency and a high-frequency component. The low-frequency components from all years were averaged to create a single mean year. Then the high-frequency component of a single year was superimposed onto the mean year to maintain quasi-realistic synoptic scale space-time variability. The criterion for choosing a particular year for the high-frequency component was to maximise the variance of the OMIP-forcing relative to the variance of the original ERA data. For dynamical consistency it was considered desirable to choose only one high-frequency year for all forcing products (winds, temperatures etc). As different products have maximum variance in different years, the maximisation of variance was arbitrarily 
limited to zonal wind stress. This resulted in the choice of the year 1982, with preservation of $78 \%$ of the original ERA variability relative to monthly means. For the purposes of this study $2 \mathrm{~m}$ air and dewpoint temperatures, precipitation, cloud cover, incoming shortwave radiation, $10 \mathrm{~m}$ wind speed and surface wind stress from the OMIP-forcing are used.

Introducing $Q_{s r f}$ to denote either $Q_{w}$ or $Q_{i}$ in Eqn 26 the surface heat balance is given by

$$
Q_{s r f}=Q_{s r f}^{s e}+Q_{s r f}^{l a}+Q_{s r f}^{l w}+Q_{s r f}^{s w}
$$

where $Q_{s r f}^{s e}, Q_{s r f}^{l a}, Q_{s r f}^{l w}$ and $Q_{s r f}^{s w}$ are parameterisations of the sensible, latent, longwave and shortwave heat fluxes, respectively.

Following Oberhuber (1993) the turbulent fluxes are parameterised as

$$
\begin{aligned}
& Q_{s r f}^{s e}=\rho_{a} c_{a} C_{H} V_{10 m}\left(T_{a}-T_{s r f}\right) \\
& Q_{s r f}^{l a}=\rho_{a} L_{s r f} C_{L} V_{10 m}\left(q_{a}-q_{s r f}\right)
\end{aligned}
$$

Constants $\rho_{a}, c_{a}$ and $L_{s r f}$ denote the air density, the air specific heat capacity and the latent heat of vaporisation or sublimation as appropriate. The $10 \mathrm{~m}$ wind speed $V_{10 \mathrm{~m}}$ and $2 \mathrm{~m}$ air temperature $T_{a}$ are taken as prescribed forcing. Variable coefficients of sensible $C_{H}$ and latent $C_{L}$ heat transfer are formulated according to Large and Pond (1982). The surface temperature $T_{s r f}$ represents either the ocean model upper layer temperature or the sea ice/snow layer skin temperature as in Eqn 28. The specific humidity $q$ is a function of water vapor pressure $e$ (units of Pascal) and air pressure $p$ (currently approximated by a constant $1000 \mathrm{hPa}$ in MPI-OM-1).

$$
q=(0.623 e) /(p-0.378 e)
$$

At the $2 \mathrm{~m}$ level $\left(q_{a}\right)$ the water vapor pressure is a function of dew point temperature, while at the surface $\left(q_{s r f}\right)$ the saturation vapor pressure is a function of the water or ice/snow surface temperature. In both cases the vapor pressures $(e)$ are calculated according to the formulae of Buck (1981).

The radiant fluxes are parameterised as

$$
\begin{aligned}
& Q_{s r f}^{l w}=\varepsilon \sigma T_{a}^{4}(.39-.05 \sqrt{e / 100})\left(1-\chi n^{2}\right)+4 \varepsilon \sigma T_{a}^{3}\left(T_{s r f}-T_{a}\right) \\
& Q_{s r f}^{s w}=\left(1-\alpha_{s r f}\right) Q^{i n c s w}
\end{aligned}
$$

The parameterisation of net longwave radiation is based on that of Berliand and Berliand (1952), with the fractional cloud cover $n$ taken as prescribed forcing. The surface thermal emissivity and Stefan-Boltzmann constant are denoted by $\varepsilon$ and $\sigma$ respectively. The saturation vapor pressures $e$ depend on water or sea ice/snow conditions and are also calculated according to the formulae of Buck (1981). The cloudiness factor $\chi$ is a modified form of that proposed by Budyko (1974) and is a function of latitude $\phi$.

$$
\chi=0.5+0.4\left(\min \left(|\phi|, 60^{\circ}\right)\right) / 90^{\circ}
$$

The incident shortwave radiation $Q^{i n c s w}$ is provided as part of the forcing data and implicitly modified by cloud cover in the ERA model. The surface reflectivity $\alpha_{s r f}$ in Eqn 60 is either that appropriate for open water or takes one of four possible values determined by both the absence or presence of snow and by whether the surface 
temperature of the sea ice or snow is below $0^{\circ} \mathrm{C}$ (freezing) or equal to $0^{\circ} \mathrm{C}$ (melting).

$$
\alpha_{s r f}=\left\{\begin{array}{cc}
\alpha_{w} & \text { open water } \\
\alpha_{i m} & \text { sea ice surface and melting } \\
\alpha_{i f} & \text { sea ice surface and freezing } \\
\alpha_{s m} & \text { snow surface and melting } \\
\alpha_{s f} & \text { snow surface and freezing }
\end{array}\right.
$$

Over open water $Q_{w}^{s w}$ is allowed to penetrate beyond the upper model layer with an exponential decay profile.

The surface freshwater forcing effect on sea level displacement is given by

$$
Q_{\zeta}=P-E+R+G
$$

where $P, E, R$ and $G$ are fluxes of freshwater in units of $\mathrm{m} \mathrm{s}^{-1}$ due to precipitation, evaporation, river runoff and glacial meltwater, respectively. For the ocean only simulations considered here $P$ is taken as prescribed forcing, $R$ is taken from the observed mean monthly discharge of the world's 50 largest rivers (Dümenil et al., 1993), and $G$ is neglected. Finally, $E$ is calculated from the latent heat flux (Eqn 57) as

$$
E=Q_{s r f}^{l a} /\left(L_{s r f} \rho_{w}\right)
$$

where $\rho_{w}$ is the density of sea water and $L_{s r f}$ is once again the latent heat of vaporisation or sublimation as appropriate for water or ice/snow surfaces respectively. The corresponding change in surface model layer salinity $\Delta S_{1}$ is given by

$$
\Delta S_{1}=\left(\frac{\Delta z_{1}+Q_{\zeta}}{\Delta z_{1}}\right) S_{1}+\left(S_{1}-S_{o b s}\right) / S_{R}
$$

where $S_{R}$ is a time-linear restoring coefficient (units $\mathrm{s}^{-1}$ ), and $S_{o b s}$ is a prescribed observed (monthly or annual) surface salinity. Salinity restoring for the experiments considered in Section 5 has a timescale (inverse) of 39 days which is quite strong. The salinity restoring helps to correct for an unbalanced globally integrated surface freshwater flux, along with errors in the poorly known forcing fields $(P, R$, and $G)$. The restoring has the positive effect of reducing long term model drift. However, it does damp model variability. A more thorough discussion of the effects of surface relaxation is given by Killworth et al. (2000).

Momentum forcing by atmospheric wind stress over sea ice is applied directly in Eqn. 20. For the ocean surface layer velocity $\overrightarrow{v_{1}}$, the wind stress over open water and the ocean-ice stress otherwise result in a change of

$$
\frac{\partial \overrightarrow{v_{1}}}{\partial t}=\frac{1-I}{\rho_{w} \Delta z_{1}} \overrightarrow{\tau_{a}}+\frac{I}{\rho_{w} \Delta z_{1}} \overrightarrow{\tau_{i}}
$$

where the ice to ocean stress $\overrightarrow{\tau_{i}}=-\overrightarrow{\tau_{o}}$ from Eqn 21 .

\section{Results}

The MPI-OM-1 model formulated on the standard MPIfM grid (Fig. 2) was run for 450 years with OMIP-forcing and a vertical resolution of 23 layers having thicknesses of $20,20,25,25,25,25,25,30,45,60,90,120,150,180,210,250,300,400,500$, $600,700,900$ and $1400 \mathrm{~m}$ from top to bottom respectively. The model timestep 
was 36 minutes. Numerical values for model constants and parameters are given in Tab. 1.

The model was initialised with annual mean data from the gridded World Ocean Atlas 1998 (hereafter WOA98; Levitus et al., 1998). In the initial year threedimensional Newtonian (linear) relaxation of the thermohaline fields (temperature and salinity) was applied to all wet grid points below the fourth model layer. An additional Newtonian relaxation of surface salinity to the initial annual mean state (WOA98) with a time constant of 39 days was applied throughout the model run to avoid excessive drifting. Here we examine the model mean state over the final 51 years (i.e. 400-450) of the simulation. Since the BBL scheme is new an additional 101 year sensitivity simulation was run corresponding to years 350-450 of the control integration and initialised with the model state at the end of year 349 of the control integration.

\subsection{Control Integration}

The decadal mean vertically integrated barotropic velocity streamfunction is shown in Fig. 4. The streamfunction shows a massflux of approximately $170 \mathrm{~Sv}$ through Drake Passage. The most widely accepted observational estimate is $134 \pm 14 \mathrm{~Sv}$ (Nowlin and Klinck, 1986) with OGCMs ranging from 120-200 Sv (Cai and Baines, 1996). As discussed below, the convection in the Weddell Sea in MPI-OM-1 is somewhat excessive in the current setup with the OMIP-forcing and the induced changes in the density structure contribute to the increased strength of the Antarctic Circumpolar Current (ACC). The North Atlantic cell associated with the Gulf Stream and the North Pacific cell associated with the Kuroshio Current have maxima of 39 and 51 Sv respectively. While the North Atlantic cell associated with the Gulf Stream is somewhat weak it is in reasonable agreement with other z-coordinate OGCMs (e.g. Gent et al., 1998).

The global and Atlantic meridional overturning streamfunctions are shown in Fig. 5. The northern hemisphere cell has a global maximum of $14.9 \mathrm{~Sv}$ at a depth of $840 \mathrm{~m}$ at $39^{\circ} \mathrm{N}$. This quantity is associated with the production of North Atlantic Deep Water (NADW) which has a peak of $15.7 \mathrm{~Sv}$ (also at $840 \mathrm{~m}, 39^{\circ} \mathrm{N}$ ) and an outflow at $30^{\circ} \mathrm{S}$ of $11.9 \mathrm{~Sv}$ at $1050 \mathrm{~m}$. The southern hemisphere deep cell has a maximum of $31.5 \mathrm{~Sv}$ at the equator and an inflow of $18.5 \mathrm{~Sv} \mathrm{AABW}$ at $30^{\circ} \mathrm{S}$, both at $3800 \mathrm{~m}$ depth. The Southern Ocean cell attains a maximum of $9.3 \mathrm{~Sv}$ at $1600 \mathrm{~m}$ depth and $68.5^{\circ} \mathrm{S}$. The shallow tropical-subtropical overturning cells (STCs) are also evident with the usual asymmetry in the Atlantic. A reasonable simulation of the main features of the overturning streamfunction is crucial for climate studies with coupled OAGCMs. In general, we find that the streamfunction of MPI-OM-1 is significantly improved with respect to HOPE, the latter being characterised by a too weak NADW cell and a too strong Southern Ocean cell. Also we note that the results from the MPI-OM-1 ocean model are quite sensitive to choice of the salinity field used for the surface relaxation. In particular, the Arctic Ocean surface salinities are somewhat fresher in the WOA98 gridded dataset than in WOA94 (Levitus et al., 1994). Comparison of a 120 year run of a beta version of MPI-OM-1 (no isopycnal diffusion and no Gent and McWilliams mixing) showed a weakening of the NADW of around $4 \mathrm{~Sv}$ for SSS restoring to WOA98 compared to WOA94 (not shown).

Global and Atlantic poleward transports of heat implied by the net surface atmosphere-ocean heat flux are shown in Fig. 6. For the global ocean MPI-OM-1 
compares well with the direct observations. The model is also in reasonable agreement with estimates derived via bulk formula from both the OMIP-forcing and NCEP-NCAR climatologies in the northern hemisphere (not shown). South of $30^{\circ} \mathrm{S}$ the global transports from the OMIP-forcing and NCEP-NCAR reanalysis are of opposite sign. At least partly, this discrepancy arises from the derivation of the turbulent heat fluxes in the absence of a fractional sea ice cover for both of the climatologies. In the northern hemisphere the maximum global heat transport is $1.43 \mathrm{PW}$ at $18^{\circ} \mathrm{N}$. In the Atlantic Ocean the MPI-OM-1 heat transports are everywhere too weak when compared to estimates derived from in situ observations, but in reasonable agreement with the estimates derived from top of the atmosphere observations by removing atmospheric heat transports. The in situ observed maximum of $1.39 \pm 0.25 \mathrm{PW}$ at $11^{\circ} \mathrm{N}$ compares with $0.76 \mathrm{PW}$ at $11^{\circ} \mathrm{N}$ and a maximum of $0.84 \mathrm{PW}$ at $21^{\circ} \mathrm{N}$ in the MPI-OM-1 model.

Late summer and late winter sea ice thickness for both hemispheres is shown in Fig. 7. In the northern hemisphere the sea ice spatial distribution compares relatively well with satellite observations (e.g. Gloerson et al., 1992). One exception is that there is too much simulated sea ice in the Greenland Sea and Denmark Strait. For example, the sea ice never reaches Iceland in the mean monthly satellite observations over the lifetime of the SMMR satellite (1978-86). Also the observed coastal leads along the Canadian and Alaskan coastlines are not reproduced by the model. The thickness of Arctic sea ice is only poorly observed which makes it difficult to evaluate the quality of the modelled pack. The modelled southern hemisphere winter sea ice thickness is generally in the range 0.4-0.6 m. Thicker ice occurs along the coastline of the western Weddell Sea, the western Ross Sea, and in the Bellingshausen Sea. In summer the Southern Ocean sea ice nearly completely disappears except for the thick ice in the western Weddell Sea and some thin ice in the Ross Sea. When compared to satellite observations (Gloerson et al., 1992) it can clearly be seen that the model underestimates the March sea ice distribution particularly in the Eastern Ross, Amundsen, Bellingshausen and Weddell Seas.

The maximum depth of convective overturn driven by surface forcing is shown in Fig. 8. There is a widespread region of convection to depths 500-1000 m associated with the North Atlantic Current inflow to the Greenland Sea. Further northward, Greenland Sea convection to $1500-1750 \mathrm{~m}$ can be seen, with three highly localised sites where maxima of $2000 \mathrm{~m}$ are attained. In the Labrador Sea the modelled convection penetrates within the range $1250-2500 \mathrm{~m}$. Both the Labrador and Greenland Sea convection depths are in reasonable agreement with the spatio-temporally sparse available observations (e.g. Marshall and Schott, 1999). In the Irminger Basin the model convection to between 1250 and $1750 \mathrm{~m}$ has not been observed, although it is not an uncommon feature of OGCMs. The main convective region in the Southern Ocean is in the Weddell Sea. In the MPI-OM-1 simulation convection to abyssal depths $(4000 \mathrm{~m})$ is widespread here. Although abyssal convection has been observed in the Weddell Sea (e.g. Gordon, 1978) the observations are limited in time and space, so no direct comparison can be made with the integration considered here. However, it is most likely that the modelled Weddell Sea convection is still too strong. A contributing factor is the relatively coarse vertical resolution that is not able to resolve the very sensitive relationship between mixed layer depth, sea ice growth and buoyancy instability (Martinson and Iannuzzi, 1998). A surface manifestation of the Weddell Sea deep convection in MPI-OM-1 is the occurrence of a small permanent polynya around $60^{\circ} \mathrm{S}, 30^{\circ} \mathrm{W}$. The choice of the enhanced diffusion convection scheme was motivated by closure of much larger polynyas which are 
present in both the Weddell and Ross Seas when the traditional convection scheme is used in MPI-OM-1 under the OMIP-forcing (not shown). The Weddell polynya is also quite sensitive to the surface fresh water flux, and it can be expected that inclusion of a glacial melt scheme for the Antarctic would help in its removal by adding stability to the water column (Marsland and Wolff, 2001). Deep convection can also be seen to $1600 \mathrm{~m}$ in the Ross Sea and offshore of Prydz Bay $\left(70^{\circ} \mathrm{E}\right)$. In the southern hemisphere there is also convection to intermediate depths associated with the path of the ACC (not shown). Typically such convection is to $250 \mathrm{~m}$, with deeper convection (500-750 m) in sectors of the Indian and Western Atlantic Oceans.

Fig. 9 shows a section of temperature with depth through the western Atlantic and Arctic Oceans. The western Atlantic section is inspired by the similar GEOSECS (1980) section. Also shown is the difference from the initial state (WOA98). There are two regions where large differences in temperature are found. Firstly, there is a strong warming in the upper $1000 \mathrm{~m}$ in the northern hemisphere associated with the mismatch between the observed and modelled Gulf Stream path. This is a common feature of the Gulf Stream separation problem in OGCMs (e.g. Dengg et al., 1996). Secondly, there is a strong cooling to $1600 \mathrm{~m}$ around $45^{\circ} \mathrm{S}$ associated with the poor simulation of Antarctic Intermediate Water (AAIW; see the discussion of salinity below). In the Southern Ocean (and the abyssal waters of the southern hemisphere) there is a slight cooling due to the too strong mixing associated with the excessive strength of convection in the Weddell Sea. Finally, it can be seen that the intermediate (100-1500 m) waters of the Greenland Sea are too warm by approximately $2^{\circ} \mathrm{C}$. This results from a too deep North Atlantic inflow.

The corresponding section for salinity is shown in Fig. 10. Many features are similar to those in the temperature section. The Gulf Stream mismatch results in much fresher salinity in the upper $1000 \mathrm{~m}$ of the North Atlantic. The loss of AAIW results in saltier intermediate waters that extend from a source region near $45^{\circ} \mathrm{S}$ to approximately $20^{\circ} \mathrm{N}$. It remains unclear why the AAIW is so poorly simulated given that other models have seen marked improvement of AAIW maintenance in simulations that included isopycnal diffusion and a Gent and McWilliams mixing parameterisation (e.g. Hirst and McDougall, 1996). One possibility is that since the ACC strength is somewhat stronger than observed the time for surface waters to cross the South Pacific from west to east is too short and the associated cooling that provides a source for AAIW production is hence underestimated. The strong mixing by convection results in slightly decreased salinities in the Weddell Sea and in the abyssal waters. The too strong North Atlantic inflow into the Greenland Sea produces a salinity increase in the upper $100-800 \mathrm{~m}$. There are also large salinity errors of both signs in the upper $100 \mathrm{~m}$ of the Arctic Ocean. However, it is reassuring that the model at least maintains a strong Arctic halocline.

\subsection{Bottom Boundary Layer Sensitivity}

Introduction of the BBL parameterisation of slope convection can be expected to have a significant impact on the simulation of the overflows across the Greenland Scotland Ridge. Here dense water originating from the Nordic seas crosses the sill through the Faeroe Bank Channel and the Denmark Strait. These dense water masses form the core of the lower NADW. In Fig. 11 the difference in bottom density that results from the introduction of the BBL scheme is shown. Generally, considerably higher bottom densities indicating a less diluted overflow can be found 
all along the pathway of the overflow waters. The dense water plume continues from the Irminger basin into the Labrador Sea following the course of the Deep Western Boundary Current.

With respect to the North Atlantic Ocean, inclusion of the BBL scheme has a variety of other beneficial impacts on the simulation. The maximum in meridional overturning streamfunction of the NADW cell is increased by approximately $1 \mathrm{~Sv}$ or $7 \%$ (not shown). The strength of the Deep Western Boundary Current, which is very weak in the run without BBL, is greatly enhanced (not shown). The simulation of North Atlantic convection is improved in all three main convection sites (not shown). The maximum depth of convection is increased from 2000 to $2500 \mathrm{~m}$ in the Labrador Sea and from 1600 to $2000 \mathrm{~m}$ in the Greenland and Norwegian Seas. Also the maximum depth of the spurious convection in the Irminger Basin is reduced from 3100 to $1600 \mathrm{~m}$. These improvements result in an increased (improved) poleward heat transport in the North Atlantic (Fig 12). The difference is most prominent in the region $45-55^{\circ} \mathrm{N}$ where it is around $0.1 \mathrm{PW}$ or $25 \%$. Various indices of model performance in relation to the BBL sensitivity are summarised in Tab. 2.

The effect of the BBL on the simulation of the Mediterranean outflow is shown in Fig. 13. Clearly, the salinity maximum that is located around $1200 \mathrm{~m}$ in reality is concentrated much too high in the water column $(600 \mathrm{~m})$ in the run without a BBL scheme. The run with BBL shows some improvement in the depth of the salinity maximum. However, it should be noted that both the $1200 \mathrm{~m}$ and $500 \mathrm{~m}$ maxima are too salty even with the BBL parameterisation. This results from the relatively course horizontal model resolution of approximately $180 \mathrm{~km}$ at the Strait of Gibraltar, as opposed to the geographical strait width of $15 \mathrm{~km}$.

\section{Discussion}

The main focus of this paper is to introduce the MPI-OM-1 model as a new OGCM from the MPIfM and to outline the many distinctions between it and the HOPE model. In particular, MPI-OM-1 has an orthogonal curvilinear coordinate system and a variety of new parameterisations with respect to HOPE. We concentrate on a 450 year simulation with the standard MPIfM grid because it is this version that is used in the control and transient climate change scenario runs with the ECHAM5/MPI-OM-1 coupled model. For completeness, descriptions of the ocean and sea ice model equations, the timestepping and the treatment of surface forcing have also been provided.

A number of obvious problems remain, some of which are quite common to other OGCMs. Despite improvements from the BBL scheme, the North Atlantic poleward heat transport is still too weak when compared to observations. Most likely, the weak poleward heat transport problem in OGCMs will only find improvement through better representation of the many observed currents and gyres. The Gulf Stream in MPI-OM-1, while reasonable with respect to other coarse resolution OGCMs, is clearly at odds with the observations (e.g. lack of mesoscale variability, coastal separation). There has been some success in better representing the Gulf

Stream using regional models with much higher horizontal resolution, (e.g. POP $\frac{1}{10}^{\circ}$ North Atlantic version; www.oc.nps.navy.mil/navypop/). However, these successes have not yet been able to be repeated in global setups. Also, for currently available computing resources it remains infeasible to take this approach in coupled setups de- 
signed for the investigation of climate variability and climate change. Another issue for improving the heat transport may be increased vertical resolution. Preliminary experiments with 40 layers of a coarser horizontal resolution version (COARSE, see below) under NCEP-NCAR forcing show strengthened meridional overturning and poleward heat transport. A second major weakness of the MPI-OM-1 simulation with OMIP-forcing is the failure to renew the AAIW. As mentioned in Section 5.1 this may in part be due to the too strong ACC in the model. The ACC transport is determined by both dynamic and thermodynamic processes. The dynamic component is due to wind stress forcing (here taken as a product of the OMIP-forcing) which may be dissipated by both internal and bottom friction. In general, OGCMs require excessive internal friction for numerical stability. More likely, the MPI-OM-1 ACC transport will be damped by improving the simulation of the thermohaline structure of the Southern Ocean watermasses. In particular, improved simulation of deep convection using the subgridscale plume parameterisation may significantly aid in better representation of the frontal structures of the Southern Ocean. Also, it can be noted that the ACC strength is quite sensitive to the model's resolved topography. Inclusion of features that are currently subgridscale by increasing horizontal and vertical resolution may help to improve the transport.

Despite these failings, it is also apparent that the MPI-OM-1 model in many ways outperforms it's predecessor HOPE. In particular the strength of global meridional overturning and poleward heat transport are much improved. Additionally, a sensitivity experiment has shown that the new BBL scheme results in improvements to the model's representation of northern hemisphere deep convection sites, to the overflows of dense waters from the Arctic to the Atlantic, to the North Atlantic deep subpolar gyre circulation, to the Atlantic meridional overturning streamfunction, and to the Atlantic poleward heat transport. Also the simulation of Southern Ocean sea ice has been improved by the choice of convection parameterised by enhanced vertical diffusion rather than by convective adjustment.

The use of SSS restoring is a quite common necessity for damping large drifts in OGCMs and also for maintaining realistic simulation of both northern and southern hemisphere sea ice extent, fraction and thickness. In MPI-OM-1 with OMIP-forcing the linear time-constant of 39 days can be considered as strong restoring. Indeed, in places where the model error is large (e.g. the Gulf Stream), the contribution of the restoring term to the surface fresh water balance is at least of the order of the precipitation itself. Since a primary concern of the MPI-OM-1 model development effort has been the improvement of the ocean and sea ice component of the MPIfM coupled OAGCM for climate studies, this raises the question of how useful the model will be in coupled mode. The latest cycle of the atmospheric model ECHAM5 has been coupled to the MPI-OM-1 model version described here and a control run without heat or freshwater flux corrections has been integrated for over 250 years with T42 spectral resolution in the atmosphere. Initial results show an improved (strengthened) simulation of meridional overturning and poleward heat transport in both the global and Atlantic oceans. An example is given in Figure 14 which shows the Atlantic meridional overturning streamfunction. It can be seen that both the depth and strength of the NADW cell are improved with respect to the OMIP-forced case, which in turn leads to a strengthened poleward heat transport (not shown). Given the promising initial results of the coupled simulation, and noting that the strong SSS restoring in the OMIP-forced simulation can be relaxed by an order of magnitude under NCEP-NCAR forcing (see below), we conclude that the required strength of the restoring under OMIP-forcing is of only minor concern to the model 
development effort. Also the ENSO variability in the new coupled model is more realistic with a predominant 4 year spectral peak as opposed to the 2 year spectral peak in the old version. Additionally, the Southern Ocean sea ice is much improved with respect to the ECHAM4/HOPE cycle where a number of large scale permanent polynyas were omnipresent. Details will be described in a forthcoming special issue on the MPIfM Earth System Model components in the Journal of Climate.

Two further issues not addressed so far are the long term model drift under climatological forcing and the response of the ocean model to interannually variable forcing. These issues have been investigated using a coarser horizontal resolution version of the MPI-OM-1 model (COARSE). The COARSE version has a "north pole' spanning Greenland and a 'south pole' spanning Antarctica. This geometry maintains relatively high horizontal resolution in the sinking regions of the North Atlantic but not in the Weddell Sea. Also the meridional equatorial grid refinement of the standard MPIfM grid is not included. The coarser horizontal grid geometry allows for an increase in timestep to 2.4 hours. In conjunction with the reduced computational matrix this yields approximately a 5 times speedup in integration time. The COARSE version has been integrated for 1000 years with OMIP-forcing. Additionally, experiments have been run with the NCEP-NCAR 1949-1998 reanalysis daily forcing (Kalnay, 1996).

The 1000 year OMIP-forcing simulation with the COARSE MPI-OM-1 version shows an increase in both global average temperature and salinity at 30, 215, 700 and $2200 \mathrm{~m}$ depths. This is related to imbalances in the global average surface heat and freshwater fluxes, due to mismatches between the model state and the prescribed forcing. The near surface $(30$ and $215 \mathrm{~m})$ drifts become relatively stable after 200 years, the intermediate depth drifting $(700 \mathrm{~m})$ becomes relatively stable after 400 years, while the deep drifting $(2200 \mathrm{~m})$ is comparatively linear throughout the simulation. When considering basin scale averages of temperature and salinity it can be seen that most of the drift in deep water properties can be attributed to the Pacific and Southern Oceans. In the North Atlantic and Arctic basins the deep water thermohaline drifts stabilise after approximately 300 and 700 years respectively. Nevertheless, there is little change in the meridional overturning streamfunction, the strength of poleward heat transport, and the volume and extent of sea ice in both hemispheres accompanying the thermohaline drifting when comparing between the 200 and 1000 year COARSE model states. This gives some indication that the model state described here for the standard MPIfM grid after 450 years may be indicative of the model state for a much longer integration.

Experiments using repeat cycles of the NCEP-NCAR daily forcing with the COARSE version, and a much weaker SSS restoring time constant of around 1 year, show that MPI-OM-1 is successful in reproducing many of the observed features of North Atlantic decadal ocean variability. Decadal timescale changes in the pattern of wind forcing in the Arctic are associated with the North Atlantic Oscillation (NAO) and lead to anomalously large sea ice exports through Fram Strait which in turn generate negative surface salinity anomalies in the northern North Atlantic. The time variability of these processes in the model is highly correlated to observations. For example, the model reproduces the Great Salinity Anomaly as observed at Ocean Weather Ship Bravo (Dickson et al., 1988) and the freshwater anomalies observed in the 1980's and 1990's (Belkin et al., 1998). Associated variability is seen in the strength of convection in the main North Atlantic convective sites of the Greenland and Labrador Seas. During the NAO low phase convection is reduced in the Labrador Sea and slightly enhanced in the Greenland Sea, and vice versa during 
NAO high periods. The main sensitivity is seen in the Labrador Sea and directly impacts on the lower branch of the Atlantic THC via changes in the rate of Labrador Sea Water formation and subsequent outflow into the North Atlantic Deep Western Boundary Current.

A number of studies are in progress using the MPI-OM-1 model for regional applications with the horizontal grids shown in Fig. 3. The GIN model has been coupled to a limited area atmospheric model (REMO) for process studies of the impact of mesoscale processes on the large scale ocean and sea ice system. Preliminary results show that the model reproduces observed mesoscale features such as the sea ice tongues associated with ocean eddies at the sea ice margin (pers. comm., Dimitry Sein, 2001). The BANDA version is forced with NCEP-NCAR reanalysis fields and shows good agreement with observations of the seasonal Indopacific Throughflow through the Molucca Sea and the Makassar Strait. In particular, more intense throughflow is simulated during the second half of the year. The aim of that study is to examine the climate perturbation due to the seasonal changes of SST over the north Molucca Sea. Initial results indicate a high correlation between seasonal variation of SST and the rainfall over the north Molucca Sea (pers. comm., Edvin Aldrian, 2001). The East Antarctic Mertz Glacier polynya system version (MERTZ) has been run for 20 years with OMIP-forcing and a further 10 years (1990s) with NCEP-NCAR daily reanalysis forcing. Initial results show the model simulates the Mertz polynya with realistic sea ice thickness and compactness for the local East Antarctic pack ice. Modelled sea ice production rates within the polynya are in the range 5-13 m.yr ${ }^{-1}$ which via brine rejection result in the formation of High Salinity Shelf Water (HSSW). The HSSW contributes to the formation of Adélie Land Bottom Water which is believed to contribute approximately $20 \%$ of the total AABW production (Rintoul, 1998).

\section{Acknowledgments}

We are grateful to Ernst Maier-Reimer and Uwe Mikolajewicz for developing the MPI-OM-1, Stefanie Legutke for contributions to the ocean/atmosphere coupling, Achim Stössel for contributions to the sea ice model, Dimitry Sein for discussion of the GIN setup, Edvin Aldrian for discussion of the BANDA setup, and to many coworkers at the MPIfM and the DKRZ. We also acknowledge support under the EU project PREDICATE (EVK2-CT-1999-00020), OCEAN-CLIVAR of BMBF (03F0246J9), and SFB 1626 of DFG. Finally, we are grateful to 2 anonymous reviewers for the many comments and criticisms that improved the manuscript. 
Arakawa A. and Lamb V.R. Computational design of the basic dynamical processes of the UCLA general circulation model. Methods Comput. Phys., 17:173-265, 1977.

Beckmann A. and Döscher R. A method for improved representation of dense water spreading over topography in geopotential-coordinate models. J. Phys. Oceanogr., $27: 581-591,1997$.

Belkin I.M., Levitus S. and Antonov J. Great salinity anomalies in the North Atlantic. Prog. Oceanogr., 41:1-68, 1998.

Berliand M.E. and Berliand T.G. Determining the net long-wave radiation of the earth with consideration of the effects of cloudiness. Isv. Akad. Nauk. SSSR Ser. Geofis. 1, 1952.

Bleck R. An oceanic general circulation model framed in hybrid isopycnic-Cartesian coordinates. Ocean Modelling, 4:55-88, 2002.

Bryan K. A numerical method for the study of the circulation of the world ocean. J. Computational Phys., 4:347-376, 1969.

Buck A.L. New equations for computing vapor pressure and enhancement factor. J. Appl. Met., 20:1527-1532, 1981.

Budyko M.I. Climate and life. Academic Press, Int. Geophys. Ser., 1974.

Cai W. and Baines P.G. Interactions between thermohaline- and wind-driven circulations and their relevance to the Antarctic Circumpolar Current, in a coarseresolution global ocean general circulation model. J. Geophys. Res., 101:1407314093, 1996.

Campin J.M. and Goosse H. Parameterization of density-driven downsloping flow for a coarse-resolution ocean model in z-coordinate. Tellus, 51A:412-430, 1999.

Cox G.F.N. and Weeks W.F. Salinity variations in sea ice. J. Glaciol., 13:109-120, 1974.

Dengg J., Beckmann A. and Gerdes R. The Gulf Stream separation problem. In W. Krauss, editor, The warmwatersphere of the North Atlantic Ocean, pages 253290. Gebrüder Borntraeger, Berlin, 1996.

Dickson R.R., Meincke J., Malmberg S.A. and Lee A.J. The 'Great Salinity Anomaly' in the northern North Atlantic. Prog. Oceanogr., 20:103-151, 1988.

Drijfhout S., Heinze C., Latif M. and Maier-Reimer E. Mean circulation and internal variability in an ocean primitive equation model. J. Phys. Oceanogr., 26:559-580, 1996.

Dümenil L., Isele K., Liebscher H.-J., Schröder U., Schumacher M. and Wilke K. Discharge data from 50 selected rivers for GCM validation. Report 100, MaxPlanck-Institut für Meteorologie, Hamburg, Germany, 1993.

DYNAMO Group. DYNAMO Dynamics of North Atlantic Models: Simulation and assimilation with high resolution models. Report 294, Institut für Meereskunde, Kiel, Germany, 1997. 
Eicken H. Salinity profiles of Antarctic sea ice: Field data and model results. $J$. Geophys. Res., 97:15545-15557, 1992.

Ezer T. and Mellor G.L. Simulations of the Atlantic Ocean with a free surface sigma coordinate ocean model. J. Geophys. Res., 102:15647-15657, 1997.

Fox A.D. and Maskell S.J. Two-way interactive nesting of primitive equation ocean models with topography. J. Phys. Oceanogr., 25:2977-2996, 1995.

Frey H., Latif M. and Stockdale T. The coupled GCM ECHO-2, Part I, The tropical Pacific. Mon. Wea. Rev., 125:703-720, 1997.

Gent P.R., O’Bryan F., Donabasoglu G., Doney S.C., Holland W.R., Large W.G. and McWilliams J.C. The NCAR climate system model global ocean component. J. Climate, 11:1287-1306, 1998.

Gent P.R., Willebrand J., McDougall T. and McWilliams J.C. Parameterizing eddyinduced tracer transports in ocean circulation models. J. Phys. Oceanogr., 25:463474, 1995.

GEOSECS. Atlantic expedition / sponsored by International Decade of Ocean Exploration. National Science Foundation, Washington, D.C., 1980.

Gibson J.K., Kållberg P., Uppala S., Hernandez A., Nomura A. and Serrano E. ERA description. ECMWF Re-analysis Proj. Rep. Ser. 1, Eur. Cent. for Medium-Range Weather Forecasts, Reading, England, 1997.

Gloerson P., Campbell W.J., Cavalieri D.J., Comiso J.C., Parkinson C.L. and Zwally H.J. Arctic and Antarctic sea ice, 1978-1987: Satellite passive-microwave observations and analysis. Special Publication SP-511, NASA, Washington, DC, 1992. $290 \mathrm{pp}$.

Gordon A.L. Deep Antarctic convection west of Maud Rise. J. Phys. Oceanogr., 8:600-612, 1978.

Griffies S.M. The Gent-McWilliams skew flux. J. Phys. Oceanogr., 28:831-841, 1998.

Griffies S.M., Böning C., Bryan F.O., Chassignet E.P., Gerdes R., Hasumi H., Hirst A., Treguir A.-M. and Webb D. Developments in ocean climate modelling. Ocean Modelling, 2:123-192, 2000.

Grötzner A., Latif M. and Barnett P. A decadal climate cycle in the North Atlantic Ocean as simulated by the ECHO coupled GCM. J. Climate, 11:831-847, 1998.

Hibler W.D. A dynamic thermodynamic sea ice model. J. Phys. Oceanogr., 9:815846, 1979.

Hirst A.C. and McDougall T.J. Deep-water properties and surface buoyancy flux as simulated by a z-coordinate model inluding eddy induced advection. J. Phys. Oceanogr., 26:1320-1343, 1996.

Johns W.E., Lee T.N., Zantopp R.J. and Fillenbaum E. Updated transatlantic heat flux at $26.5^{\circ} \mathrm{N}$. WOCE Newsletter, 27:15-22, 1997. 
Kalnay E. et al. The NCEP/NCAR 40 year-reanalysis project. Bull. Amer. Meteor. Soc., 77:437-470, 1996.

Killworth P.D. and Edwards N.R. A turbulent bottom boundary layer code for use in numerical ocean models. J. Phys. Oceanogr., 29:1221-1238, 1999.

Killworth P.D., Smeed D.A. and Nurser A.J.G. The effects on ocean models of relaxation toward observations at the surface. J. Phys. Oceanogr., 30:160-174, 2000 .

Kim S.-J. and Stössel A. On the representation of the Southern Ocean water masses in an ocean climate model. J. Geophys. Res., 103:24891-24906, 1998.

Kim S.-J. and Stössel A. Impact of subgrid-scale convection on global thermohaline properties and circulation. J. Phys. Oceanogr., 31:656-674, 2001.

Klinger B.A., Marshall J. and Send U. Representation of convective plumes by vertical adjustment. J. Geophys. Res., 101:18175-18182, 1996.

Large W.G. and Pond S. Sensible and latent heat flux measurements over the ocean. J. Phys. Oceanogr., 12:464-482, 1982.

Latif M. and Barnett T.P. Causes of decadal climate variability over the North Pacific and North America. Science, 266:634-637, 1994.

Latif M. and Barnett T.P. Decadal climate variability over the North Pacific and North America: Dynamics and predictability. J. Climate, 9:2407-2423, 1996.

Latif M., Stockdale T., Wolff J.-O., Burgers G., Maier-Reimer E., Junge M.M., Arpe K. and Bengtsson L. Climatology and variability in the ECHO coupled GCM. Tellus, Ser. A, 46:351-366, 1994.

Legutke S. and Maier-Reimer E. Climatology of the HOPE-G global ocean general circulation model. Technical Report 21, German Climate Computer Center (DKRZ), Hamburg, Germany, 1999.

Legutke S. and Maier-Reimer E. The impact of downslope water-transport parameterization in a global ocean general circulation model. Clim. Dyn., in press, 2001 .

Legutke S., Maier-Reimer E., Stössel A. and Hellbach A. Ocean-sea-ice coupling in a global ocean general circulation model. Ann. Glaciol., 25:116-120, 1997.

Legutke S. and Voss R. The Hamburg atmosphere-ocean coupled circulation model ECHO-G. Technical Report 18, German Climate Computer Center (DKRZ), Hamburg, Germany, 1999.

Levitus S., Boyer T.P., Conkright M.E., O’Brien T., Antonov J., Stephens C., Stathoplos L., Johnson D. and Gelfeld R. World Ocean Database 1998: Volume 1: Introduction. NOAA Atlas NESDIS 18, Ocean Climate Laboratory, National Oceanographic Data Center, U.S. Gov. Printing Office, Wash., D.C., 1998.

Levitus S., Burgett R. and Boyer T. World Ocean Atlas 1994: Vol. 3: Salinity. NOAA Atlas NESDIS 3, U.S. Gov. Printing Office, Wash., D.C., 1994. 
Macdonald A.M. and Wunsch C. Oceanic estimates of global ocean heat transport. WOCE Newsletter, 24:5-6, 1996.

Marotzke J. Influence of convective adjustment on the stability of the thermohaline circulation. J. Phys. Oceanogr., 21:903-907, 1991.

Marshall J. and Schott F. Open-ocean convection: Observations, theory, and models. Rev. Geophys., 37:1-64, 1999.

Marsland S. and Wolff J.-O. East Antarctic seasonal sea-ice and ocean stability: A model study. Ann. Glaciol., 27:477-482, 1998.

Marsland S.J. and Wolff J.-O. On the sensitivity of Southern Ocean sea ice to the surface fresh water flux: A model study. J. Geophys. Res., 106:2723-2741, 2001.

Martinson D.G. and Iannuzzi R.A. Antarctic ocean-ice interaction: Implications from ocean bulk property distributions. In M.O. Jeffries, editor, Antarctic sea ice: Physical processes, interactions and variability, volume 74 of Antarct. Res. Ser., pages 243-272. AGU, Washington D.C., 1998.

Nowlin W.D.J. and Klinck J.M. The physics of the Antarctic Circumpolar Current. Rev. Geophys., 24:469-491, 1986.

Oberhuber J.M. Simulation of the Atlantic circulation with a coupled sea ice-mixed layer-isopycnal general circulation model. Part I: Model description. J. Phys. Oceanogr., 23:808-829, 1993.

Pacanowski R.C. MOM 2, Documentation, User's Guide and Reference Manual, Version 1.0. GFDL Ocean Technical Report 3, Princeton, 1995.

Pacanowski R.C. and Philander S.G.H. Parameterization of vertical mixing in numerical-models of tropical oceans. J. Phys. Oceanogr., 11:1443-1451, 1981.

Paluszkiewicz T. and Romea R.D. A one-dimensional model for the parameterization of deep convection in the ocean. Dynamics Atmos. and Oceans, 26:95-130, 1997.

Press W.H., Flannery B.P., Teukolsky S.A. and Vetterling W.T. Numerical Recipes in C. The Art of Scientific Computing. Cambridge University Press, 1988.

Price J.F. and Baringer M. Outflows and deep water productions by marginal seas. Prog. Oceanogr., 25:162-200, 1994.

Redi M.H. Oceanic isopycnal mixing by coordinate rotation. J. Phys. Oceanogr., 12:1154-1158, 1982.

Rintoul S. On the origin and influence of Adelié Land Bottom Water. In Ocean, ice and atmosphere: Interactions at the Antarctic continental margin, volume 75 of Ant. Res. Ser., pages 151-172. AGU, Washington D.C., 1998.

Rintoul S.R. and Wunsch C. Mass, heat, oxygen and nutrient fluxes and budgets in the North Atlantic Ocean. Deep Sea Res., 38, Suppl. 1:S355-S377, 1991.

Rodgers K.B., Latif M. and Legutke S. Sensitivity of equatorial Pacific and Indian Ocean watermasses to position of Indonesian throughflow. Geophys. Res. Lett., $27: 2941-2944,2000$. 
Roeckner E., Arpe K., Bengtsson L., Christoph M., Claussen M., Dümenil L., Esch M., Giorgetta M., Schlese U. and Schulzweida U. The atmospheric general circulation model ECHAM-4: Model description and simulation of present day climate. Report 218, Max-Planck-Institut für Meteorologie, 1996.

Roeckner E., Bengtsson L. and Feichter J. Transient climate change simulations with a coupled atmosphere-ocean GCM including the tropospheric sulfur cycle. J. Climate, 12:3004-3032, 1999.

Röske F. An atlas of surface fluxes based on the ECMWF Re-Analysis - a climatological dataset to force global ocean general circulation models. Report 323, Max-Planck-Institut für Meteorologie, Hamburg, Germany, 2001.

Semtner A.J. A model for the thermodynamic growth of sea ice in numerical investigations of climate. J. Phys. Oceanogr., 6:379-389, 1976.

Stockdale T., Latif M., Burgers G. and Wolff J.-O. Some sensitivities of a coupled ocean-atmosphere GCM. Tellus, Ser. A, 46:367-380, 1994.

Stössel A. The Hamburg sea-ice model. Technical Report 3, German Climate Computer Center (DKRZ), Hamburg, Germany, 1992.

Stössel A. On the impact of sea ice in a global ocean circulation model. Ann. Glaciol., 25:111-115, 1997.

Stössel A., Kim S.-J. and Drijfhout S.S. The impact of Southern Ocean sea ice in a global ocean model. J. Phys. Oceanogr., 28:1999-2018, 1998.

Thomas M., Sündermann J. and Maier-Reimer E. Consideration of ocean tides in an OGCM and impacts on subseasonal to decadal polar motion excitation. Geophys. Res. Lett., 28:2457-2460, 2001.

Trenberth K.E. and Solomon A. The global heat balance: heat transports in the atmosphere and ocean. Clim. Dyn., 10:107-134, 1994.

UNESCO. Algorithms for computation of fundamental properties of seawater. UNESCO Technical Papers in Marine Science 44, 1983.

Venzke S., Latif M. and Villwock A. The coupled GCM ECHO-2. Part II: Indian ocean response to ENSO. J. Climate, 13:1371-1383, 2000.

Wolff J.-O., Maier-Reimer E. and Legutke S. The Hamburg Ocean Primitive Equation Model HOPE. Technical Report 13, German Climate Computer Center (DKRZ), Hamburg, Germany, 1997. 


\begin{tabular}{|c|c|c|c|}
\hline Symbol & Description & Value & Eqn \\
\hline$\overline{\alpha_{i f}}$ & freezing sea-ice albedo & 0.75 & 62 \\
\hline$\alpha_{i m}$ & melting sea-ice albedo & 0.70 & 62 \\
\hline$\alpha_{s f}$ & freezing snow albedo & 0.85 & 62 \\
\hline$\alpha_{s m}$ & melting snow albedo & 0.70 & 62 \\
\hline$\alpha_{w}$ & sea water albedo & 0.10 & 62 \\
\hline$\lambda$ & wind mixing stability parameter & $0.03 \mathrm{~kg} \mathrm{~m}^{-3}$ & 15 \\
\hline$\varepsilon$ & emissivity of sea water & 0.97 & 59 \\
\hline$\rho_{a}$ & density of air & $1.3 \mathrm{~kg} \mathrm{~m}^{-3}$ & 56,57 \\
\hline$\rho_{i}$ & density of sea-ice & $910 \mathrm{~kg} \mathrm{~m}^{-3}$ & $20,30,31,34,35,37,41$ \\
\hline$\rho_{s}$ & density of snow & $330 \mathrm{~kg} \mathrm{~m}^{-3}$ & 32 \\
\hline$\rho_{w}$ & density of sea water & $1025 \mathrm{~kg} \mathrm{~m}^{-3}$ & $1,30,32,34,35,37,41$ \\
\hline$\sigma$ & Stefan-Boltzmann constant & $5.5 \times 10^{-8} \mathrm{~W} \mathrm{~m}^{-2} \mathrm{~K}^{-4}$ & 59 \\
\hline$\Delta x$ & parallel grid distance & $\mathrm{m}$ & 10,11 \\
\hline$\Delta y$ & meridional grid distance & $\mathrm{m}$ & 10,11 \\
\hline$\Delta z$ & vertical grid distance & $\mathrm{m}$ & 8,11 \\
\hline$\Lambda_{V}$ & eddy viscosity relaxation coefficient & 0.6 & 14 \\
\hline$\Lambda_{D}$ & eddy diffusivity relaxation coefficient & 0.6 & 14 \\
\hline$c_{a}$ & specific heat capacity of air & $1004 \mathrm{~J} \mathrm{~kg}^{-1} \mathrm{~K}^{-1}$ & 56 \\
\hline$\overline{c_{w}}$ & specific heat capacity of sea water & $4.0 \times 10^{3} \mathrm{~J} \mathrm{~kg}^{-1} \mathrm{~K}^{-1}$ & $30,34,35,37$ \\
\hline$e$ & ratio of principle axis of yield ellipse & 2.0 & 25 \\
\hline$g$ & acceleration due to gravity & $9.81 \mathrm{~m} \mathrm{~s}^{-2}$ & 1 \\
\hline$k_{i}$ & thermal conductivity of sea ice & $2.17 \mathrm{~W} \mathrm{~m}^{-1} \mathrm{~K}^{-1}$ & 28,29 \\
\hline$k_{s}$ & thermal conductivity of snow & $0.31 \mathrm{~W} \mathrm{~m}^{-1} \mathrm{~K}^{-1}$ & 29 \\
\hline$z_{0}$ & wind mixing penetration depth & $40 \mathrm{~m}$ & 15 \\
\hline$A_{b}$ & PP background vertical viscosity & $1.0 \times 10^{-4} \mathrm{~m}^{2} \mathrm{~s}^{-1}$ & 14 \\
\hline$A_{w}$ & $\mathrm{PP}$ wind mixing & $5.0 \times 10^{-4} \mathrm{~m}^{2} \mathrm{~s}^{-1}$ & 14 \\
\hline$A_{V O}$ & $\mathrm{PP}$ vertical viscosity parameter & $1.0 \times 10^{-2} \mathrm{~m}^{2} \mathrm{~s}^{-1}$ & 14 \\
\hline$\overline{B_{H}}$ & biharmonic horizontal viscosity & $1.1 \times 10^{-6} \mathrm{~s}^{-1} \times\left(\Delta x^{4}, \Delta y^{4}\right)$ & 12 \\
\hline $\mathrm{BBL}_{\max }$ & maximum BBL thickness & $500 \mathrm{~m}$ & 8 \\
\hline$C$ & empirical internal ice pressure const. & 20 & 23 \\
\hline$C_{R A}$ & $\mathrm{PP}$ viscosity tuning constant & 5.0 & 14 \\
\hline$C_{R D}$ & $\mathrm{PP}$ diffusivity tuning constant & 5.0 & 19 \\
\hline$C_{W}$ & ocean-ice stress bulk transfer & 0.0045 & 21 \\
\hline$D_{b}$ & PP background vertical diffusivity & $1.0 \times 10^{-5} \mathrm{~m}^{2} \mathrm{~s}^{-1}$ & 19 \\
\hline$D_{H}$ & harmonic horizontal diffusion & $2.5 \times 10^{-3} \mathrm{~m} \mathrm{~s}^{-1} \times(\Delta x, \Delta y)$ & 17,18 \\
\hline$D_{w}$ & $\mathrm{PP}$ wind mixing & $5.0 \times 10^{-4} \mathrm{~m}^{2} \mathrm{~s}^{-1}$ & 19 \\
\hline$D_{V O}$ & PP vertical diffusivity parameter & $1.0 \times 10^{-2} \mathrm{~m}^{2} \mathrm{~s}^{-1}$ & 19 \\
\hline$L_{f}$ & latent heat of fusion & $2.5 \times 10^{6} \mathrm{~J} \mathrm{~kg}^{-1}$ & 30 \\
\hline$L_{s}$ & latent heat of sublimation & $2.834 \times 10^{6} \mathrm{~J} \mathrm{~kg}^{-1}$ & 57 \\
\hline$L_{v}$ & latent heat of vaporisation & $2.5 \times 10^{6} \mathrm{~J} \mathrm{~kg}^{-1}$ & 57 \\
\hline$P^{*}$ & empirical internal ice pressure const. & $5000 \mathrm{~N} \mathrm{~m}^{-1}$ & 23 \\
\hline$S_{i c e}$ & salinity of sea-ice & $5 \mathrm{psu}$ & 41 \\
\hline$S_{R}$ & surface salinity restoring time-constant & $3.33 \times 10^{6} \mathrm{~s}$ & 65 \\
\hline$T_{\text {freeze }}$ & freezing temperature of sea water & $-1.9^{\circ} \mathrm{C}$ & $34,35,36,37$ \\
\hline$T_{m e l t}$ & melting temperature of sea ice/snow & $0^{\circ} \mathrm{C}$ & \\
\hline$W_{T}$ & wind mixing amplitude parameter & $5.0 \times 10^{-4} \mathrm{~m}^{2} \mathrm{~s}^{-1}$ & 15 \\
\hline
\end{tabular}

Table 1: Constants and parameters used in the standard grid for climate studies of the MPI-OM-1 model. 


\begin{tabular}{|l|c|c|c|}
\hline Index & BBL & No BBL & Unit \\
\hline \hline Max. Labrador Sea convection & 2500 & 2000 & $\mathrm{~m}$ \\
\hline Max. Greenland/Norwegian Sea convection & 2000 & 1600 & $\mathrm{~m}$ \\
\hline Max. Irminger Basin convection & 1600 & 3100 & $\mathrm{~m}$ \\
\hline Global max. northward poleward heat transport & 1.43 & 1.38 & $\mathrm{PW}$ \\
\hline Global max. southward poleward heat transport & 1.26 & 1.29 & $\mathrm{PW}$ \\
\hline North Atlantic poleward heat transport $60^{\circ} \mathrm{N}$ & 0.34 & 0.30 & $\mathrm{PW}$ \\
\hline North Atlantic poleward heat transport $50^{\circ} \mathrm{N}$ & 0.50 & 0.41 & $\mathrm{PW}$ \\
\hline North Atlantic poleward heat transport $40^{\circ} \mathrm{N}$ & 0.54 & 0.48 & $\mathrm{PW}$ \\
\hline North Atlantic poleward heat transport $30^{\circ} \mathrm{N}$ & 0.75 & 0.70 & $\mathrm{PW}$ \\
\hline North Atlantic poleward heat transport $30^{\circ} \mathrm{S}$ & 0.21 & 0.19 & $\mathrm{PW}$ \\
\hline Max. NADW overturning cell & 15.7 & 14.9 & $\mathrm{~Sv}$ \\
\hline Min. AABW overturning cell & -31.5 & -30.3 & $\mathrm{~Sv}$ \\
\hline Min. Southern Ocean overturning cell & -9.3 & -9.5 & $\mathrm{~Sv}$ \\
\hline Southward transport of NADW at $30^{\circ} \mathrm{S}$ & 11.9 & 9.1 & $\mathrm{~Sv}$ \\
\hline Northward transport of AABW at $30^{\circ} \mathrm{S}$ & 18.5 & 17.8 & $\mathrm{~Sv}$ \\
\hline Faroe Bank Channel volume transport & 2.15 & 1.75 & $\mathrm{~Sv}$ \\
\hline Denmark Strait volume transport & 2.42 & 2.38 & $\mathrm{~Sv}$ \\
\hline
\end{tabular}

Table 2: Effects of the BBL slope convection scheme on various products related to global climate. The heat and volume transport indices are averages for years 400450 of the runs with (BBL) and without (No BBL) the slope convection scheme. The convection depths are maximums for the respective 51 year periods. The maximum northward and southward poleward heat transports are attained at $18.5^{\circ} \mathrm{N}$ and $10.5^{\circ} \mathrm{S}$ respectively. 


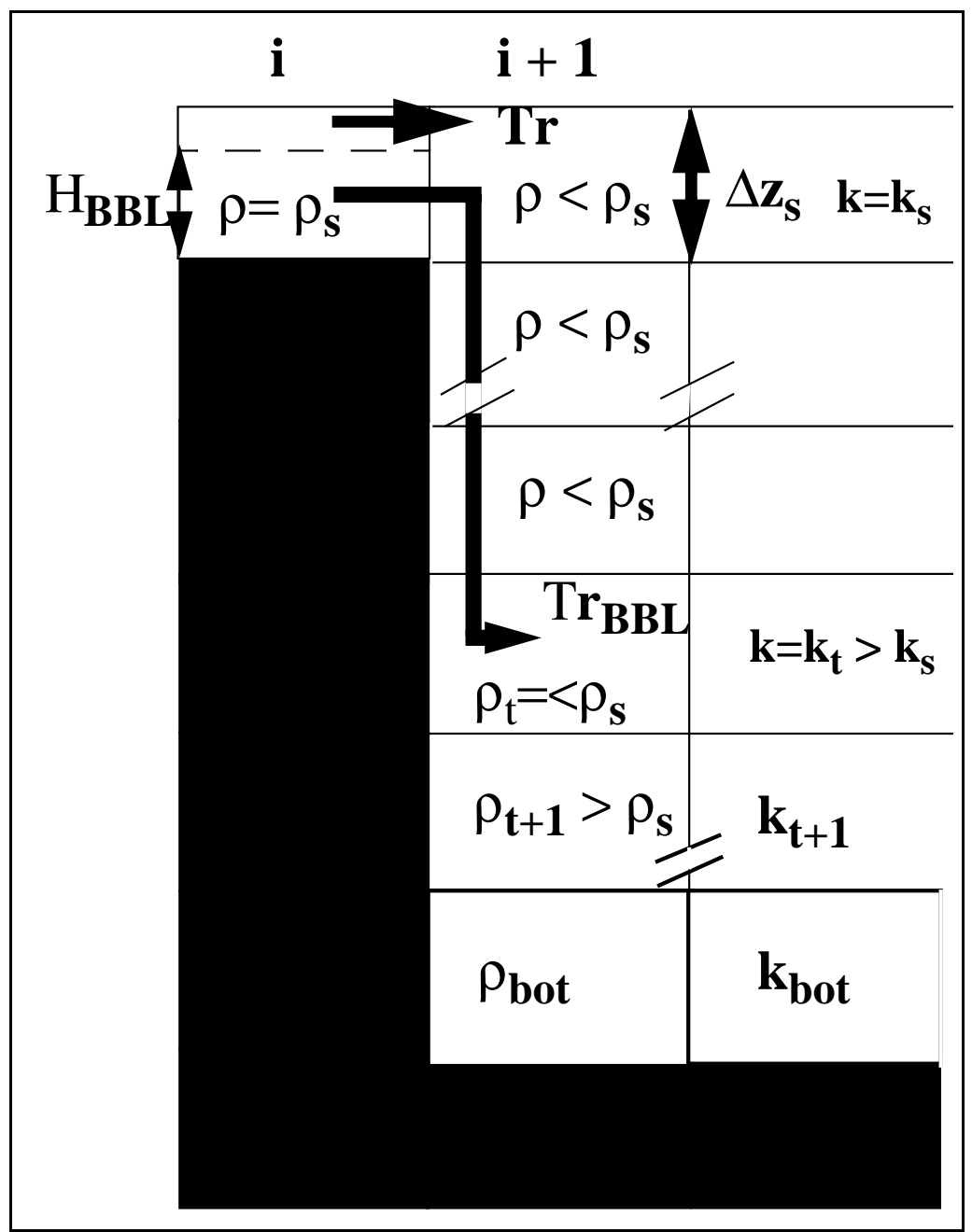

Figure 1: Schematic diagram of the bottom boundary layer advective transport to neutral density level. Model levels are indicated by $\mathrm{k}$ where $\mathrm{k}_{s}$ and $\mathrm{k}_{t}$ indicate the levels of the source and target cells respectively. The grid index i refers to either meridional or parallel directions in the curvilinear horizontal discretisation. For additional details refer to the text. 


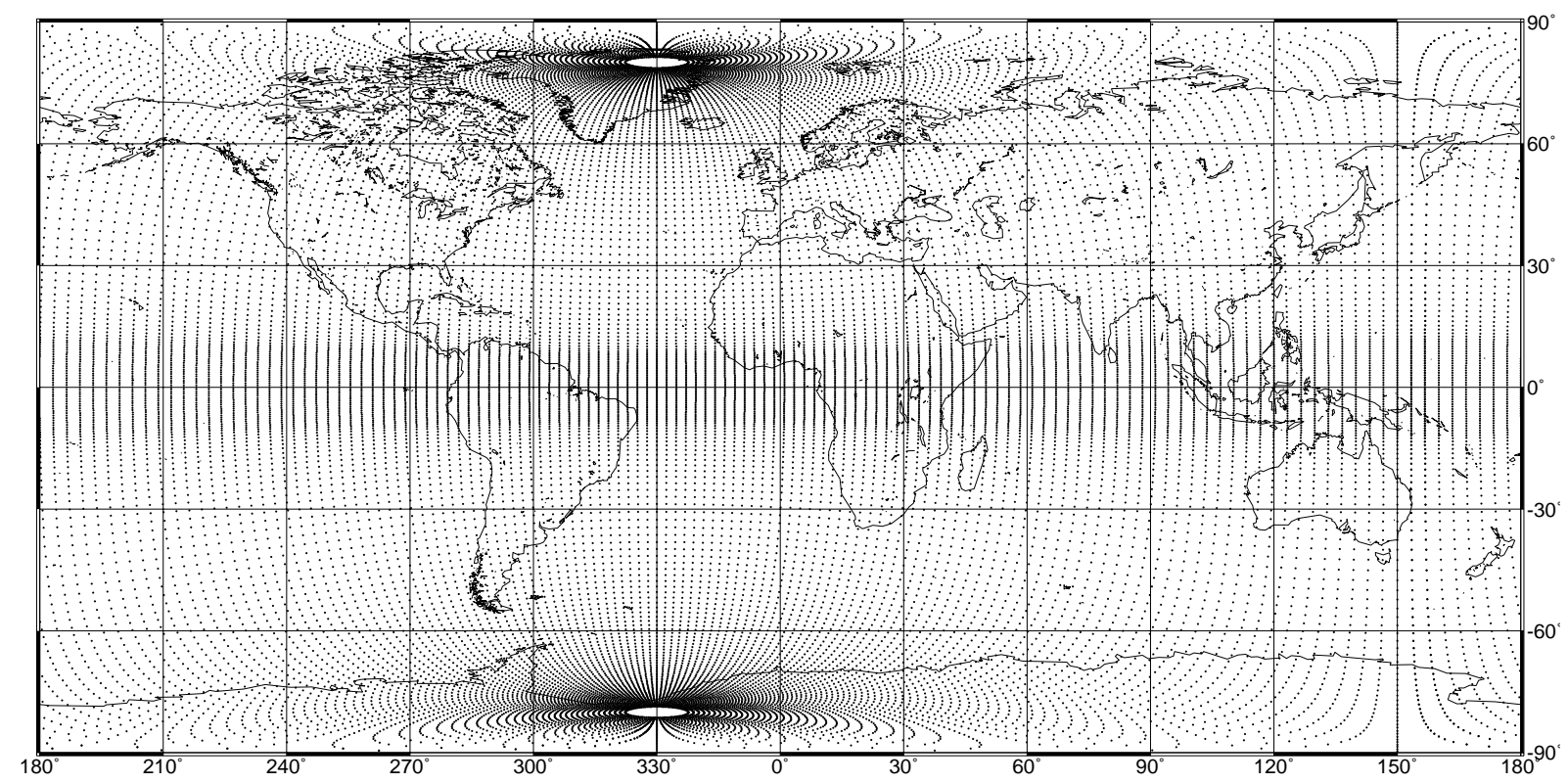

Figure 2: Standard MPI-OM-1 orthogonal curvilinear grid for global climate study applications at MPIfM. 

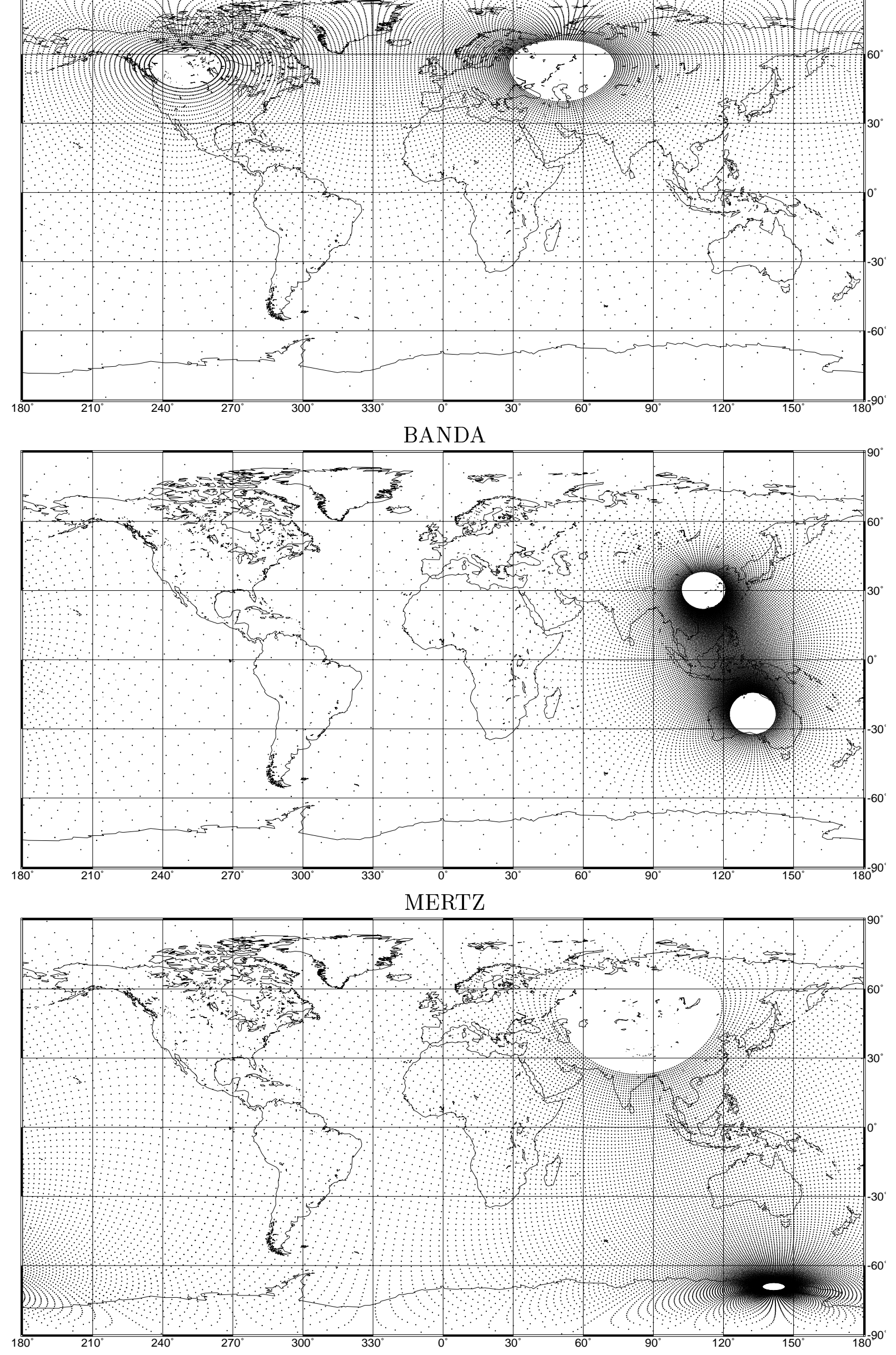

Figure 3: Three examples of application of the MPI-OM-1 orthogonal curvilinear grid to regional climate studies. 




Figure 4: Mean barotropic streamfunction averaged over years 400-450 of the control simulation. Contour interval is $10 \mathrm{~Sv}$. 


\section{GLOBAL}

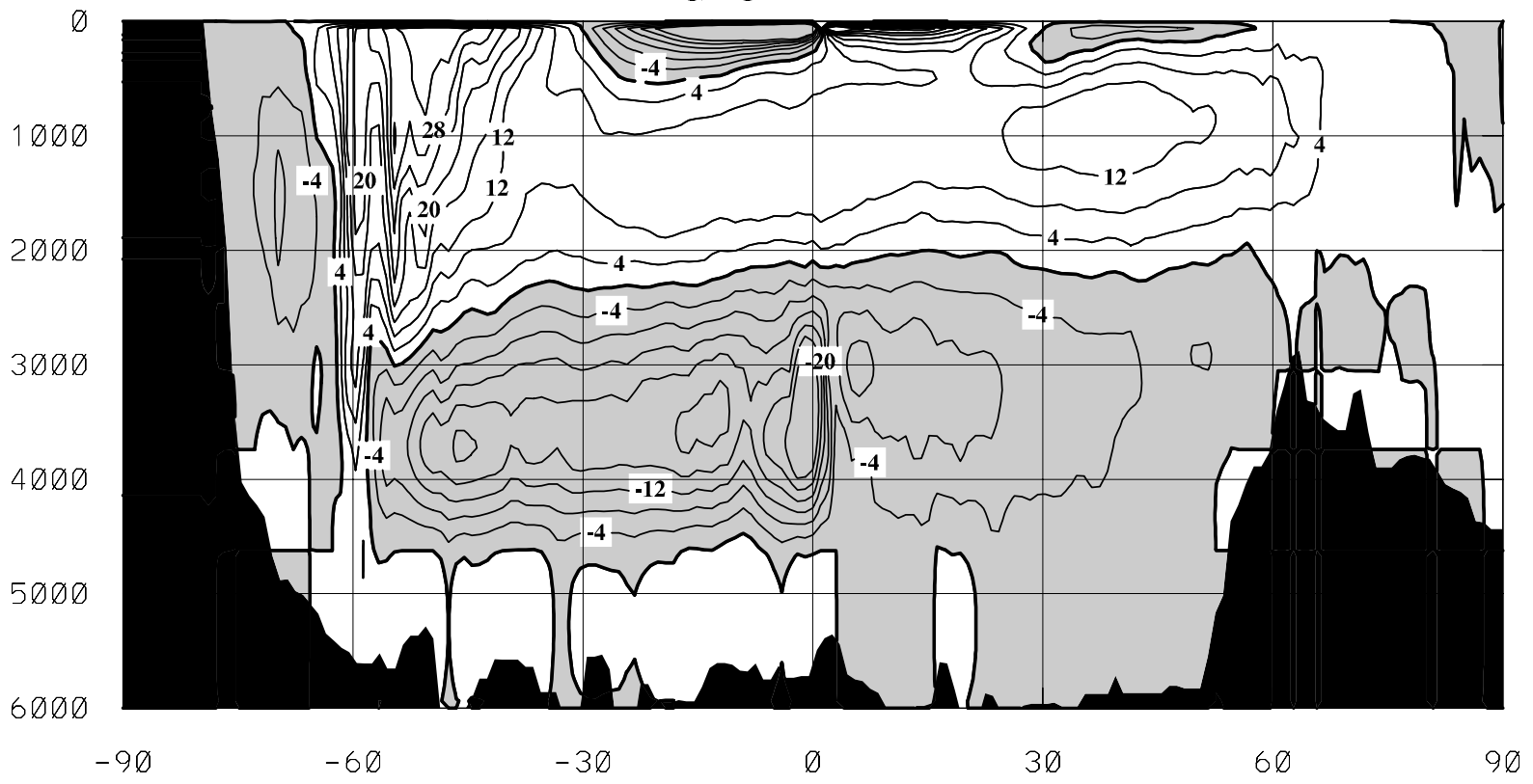

ATLANTIC

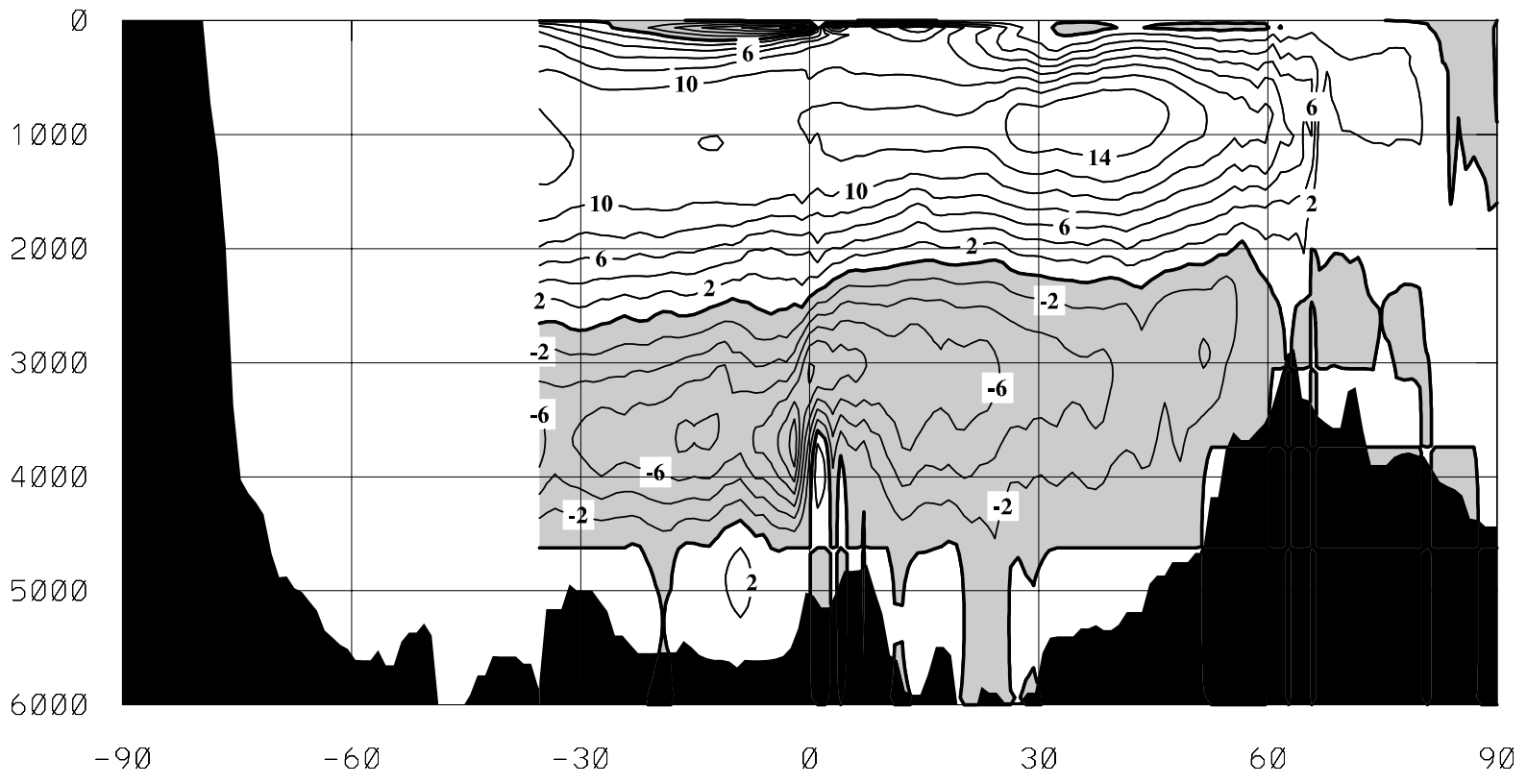

Figure 5: Mean global and Atlantic meridional overturning streamfunction averaged over years 400-450 of the control simulation. Contour interval is 4 and $2 \mathrm{~Sv}$ for the global and Atlantic respectively. Negative values are shaded. Labels show depth (ordinate) and latitude (abscissa). 

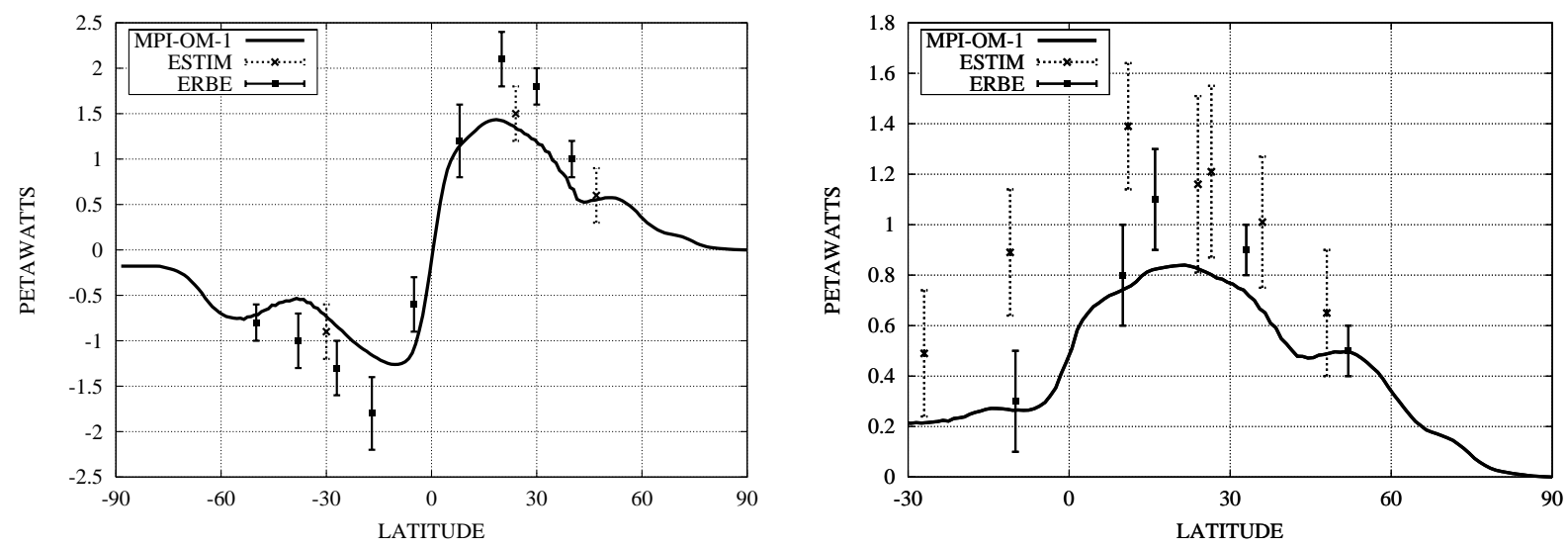

Figure 6: Meridional heat transports (PW) for the global and Atlantic oceans implied by net ocean to atmosphere heat flux. The MPI-OM-1 heat transports are averaged over the years 400-450 of the control simulation. Estimates (ESTIM) with error bars based on in situ observations are taken from Rintoul and Wunsch (1991), Macdonald and Wunsch (1996) and Johns et al. (1997). 1988 estimates derived from the top of the atmosphere as part of the Earth Radiation Budget Experiment (ERBE) and using the ERA data to remove atmospheric heat transport are taken from Trenberth and Solomon (1994). 
MARCH
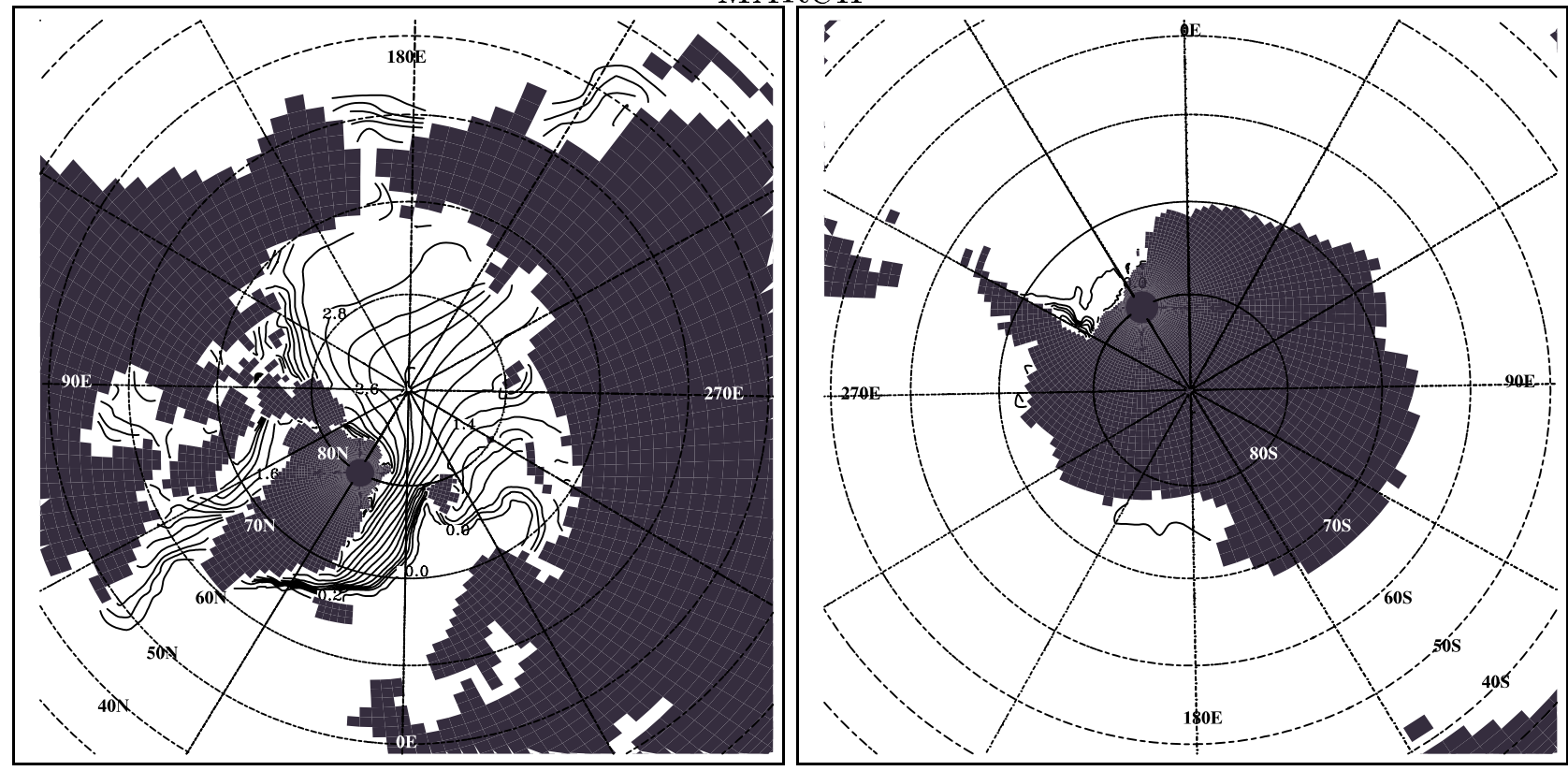

SEPTEMBER
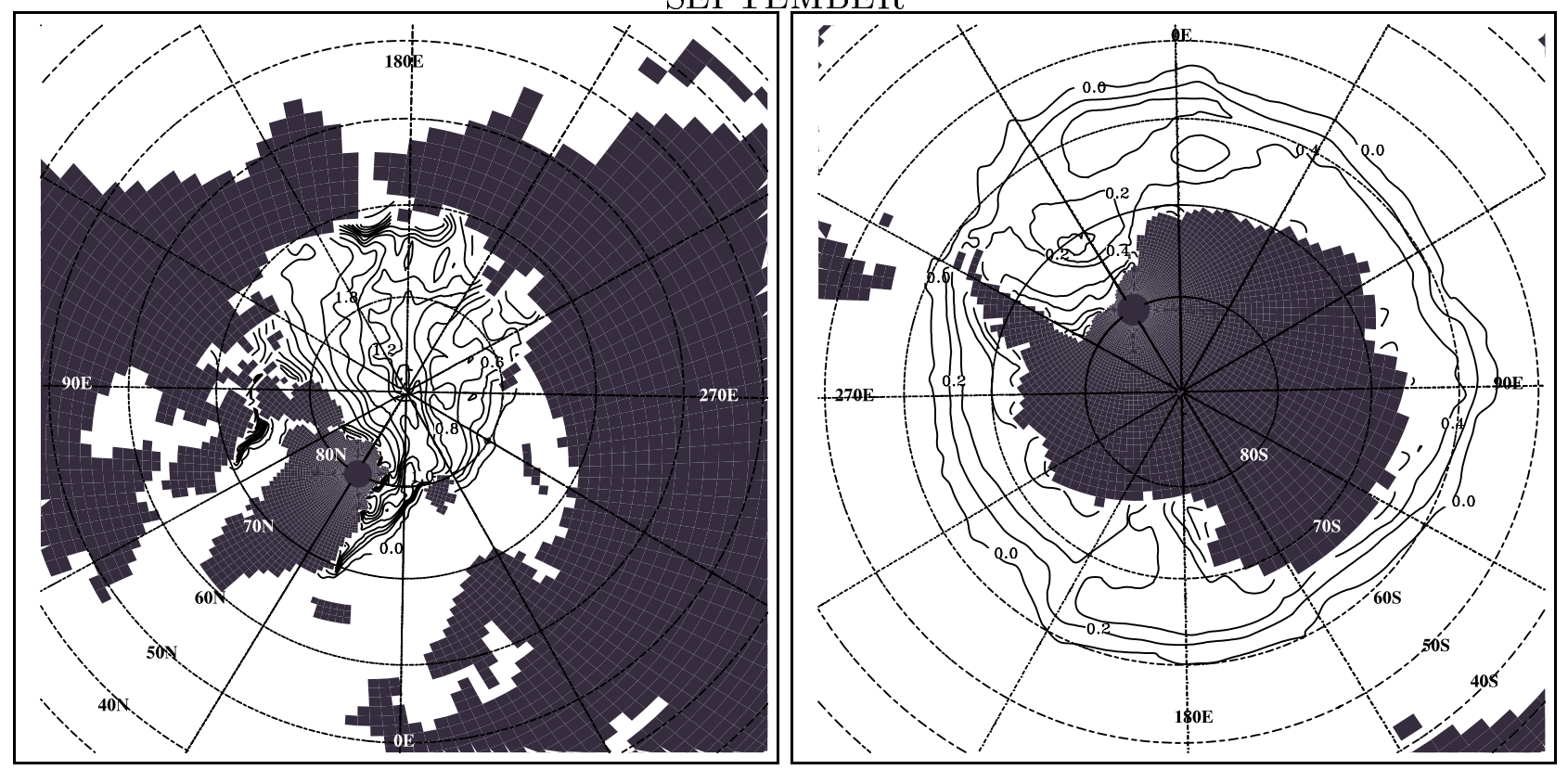

Figure 7: March and September monthly mean sea ice thickness for the Arctic (left) and Southern (right) Oceans averaged over years 400-450 of the control simulation. The contour interval is $0.2 \mathrm{~m}$. 

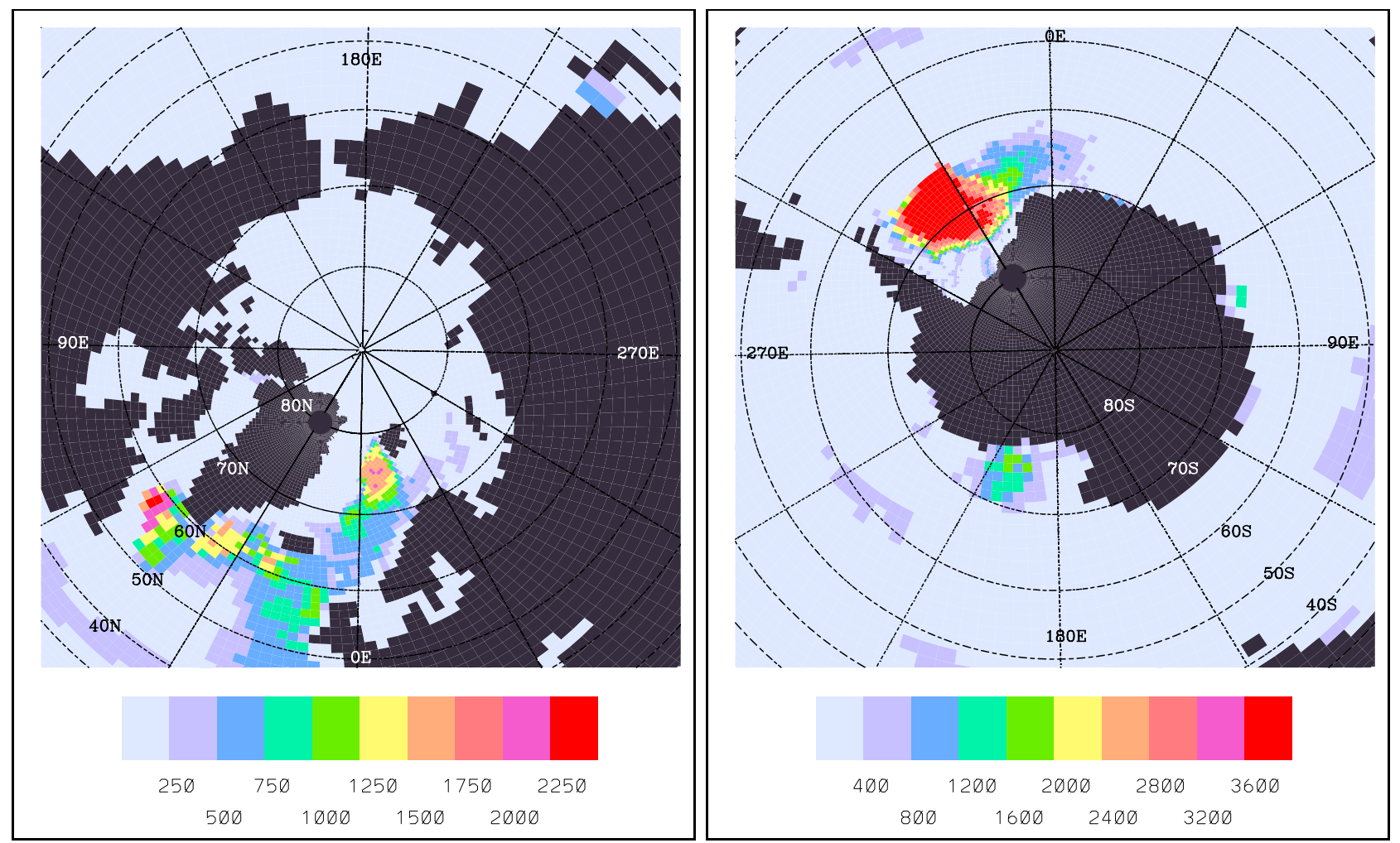

Figure 8: Maximum depth of convective overturning during the years 400-450 of the control simulation. Demarcation intervals are 250 and $400 \mathrm{~m}$ for the Arctic and Southern Oceans respectively. 

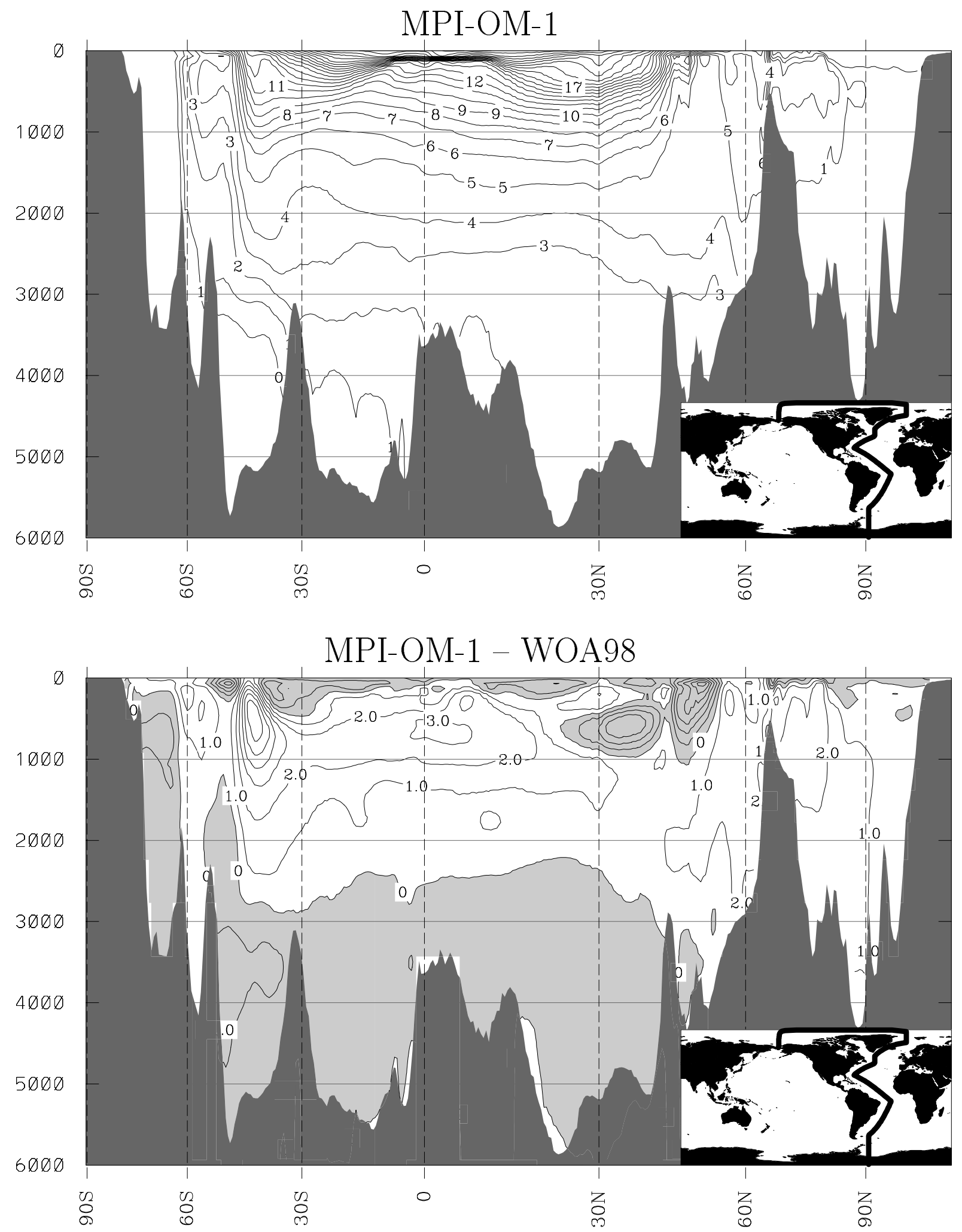

Figure 9: Temperature along a section through the Western Atlantic and Arctic oceans. The upper panel shows the mean for years 400-450 of the control simulation and the lower panel shows the difference with respect to the initial state (WOA98). Latitudes (unequally spaced) are marked on the lower axis of each panel and the depths are shown in units of $\mathrm{m}$. The inset shows the geographic location of the section. The contour interval is $1{ }^{\circ} \mathrm{C}$ and negative values are shaded in the difference plot. 

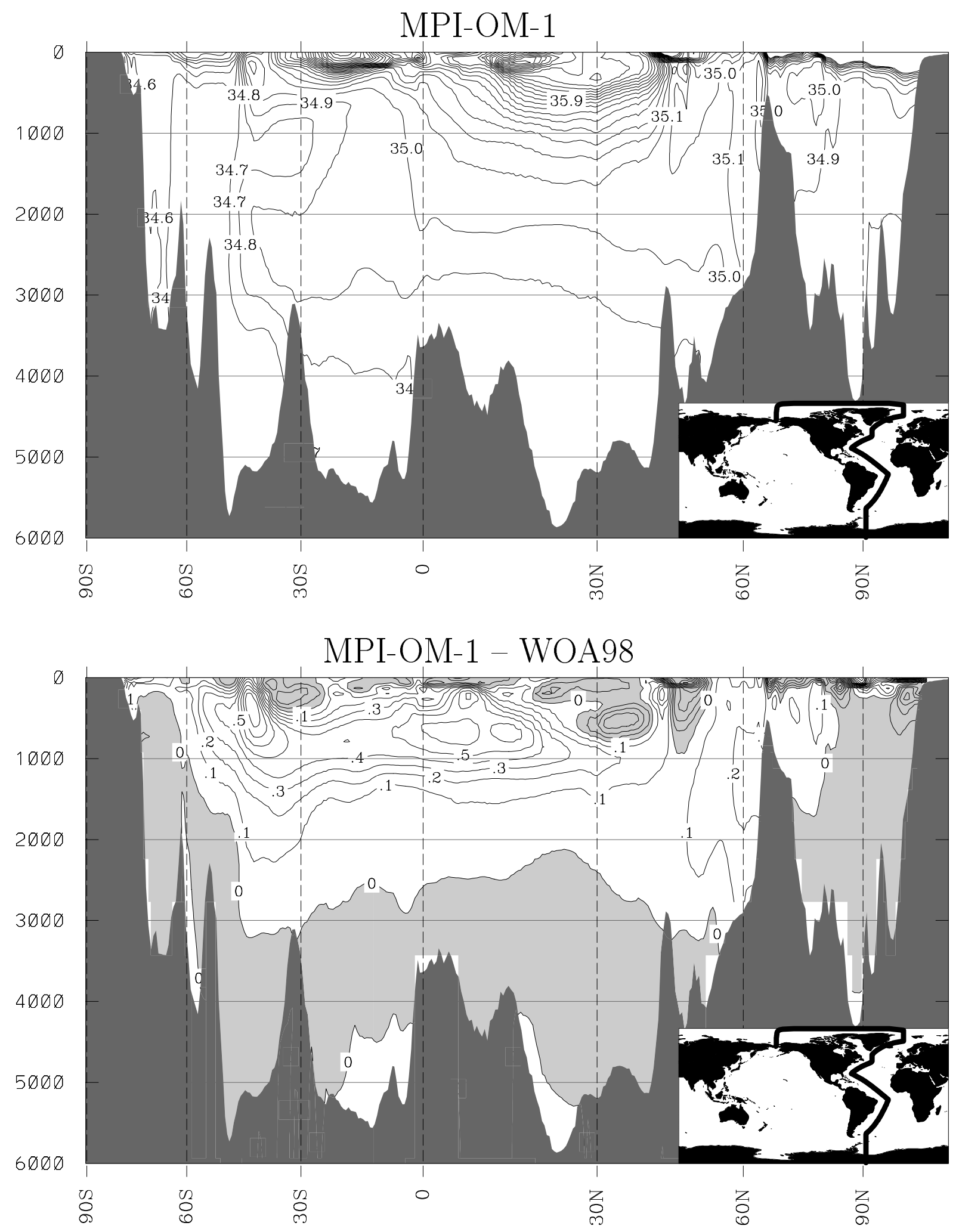

Figure 10: As in Fig. 9 but for salinity. The contour interval is 0.1 psu. 


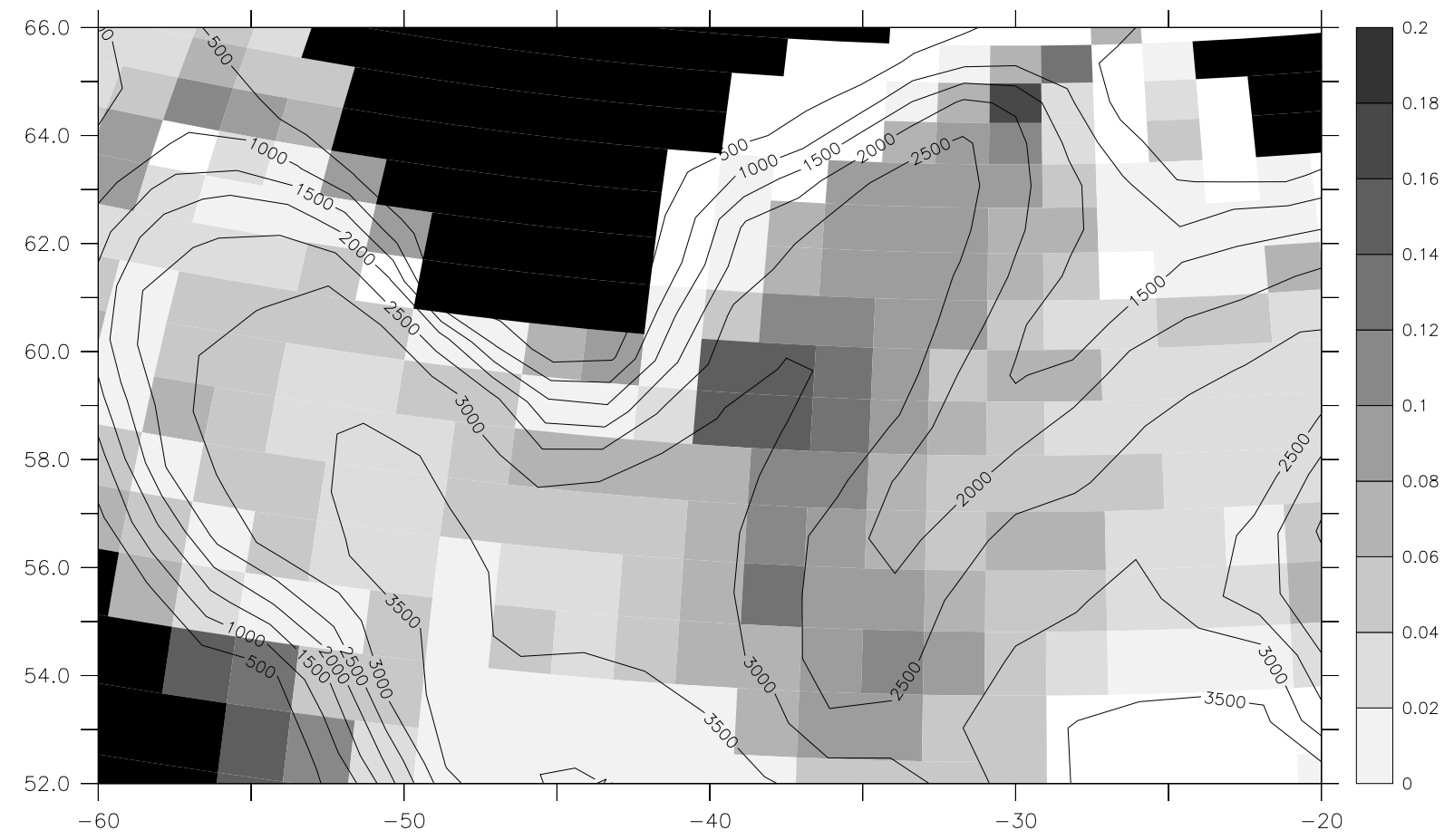

Figure 11: Effect of the slope convection scheme on bottom density $\left(\mathrm{kg} \mathrm{m}^{-3}\right)$ downstream of the Greenland Scotland Ridge. Contours show bottom depth $(\mathrm{m})$. The shading indicates the difference in density averaged over years 400-450 for the run with the BBL slope convection scheme minus the run without the BBL slope convection scheme. Labels show latitude (ordinate) and longitude (abscissa). 


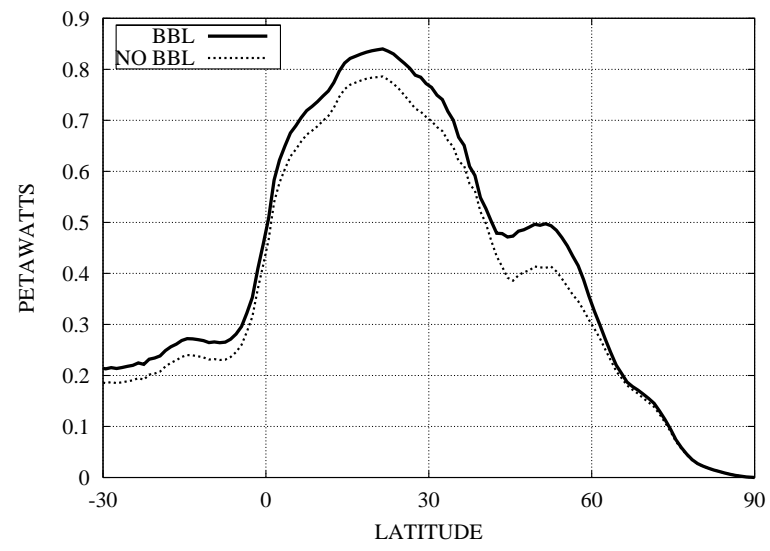

Figure 12: Atlantic meridional heat transport (PW) averaged over years 400-450 for the runs with and without the BBL slope transport scheme. 

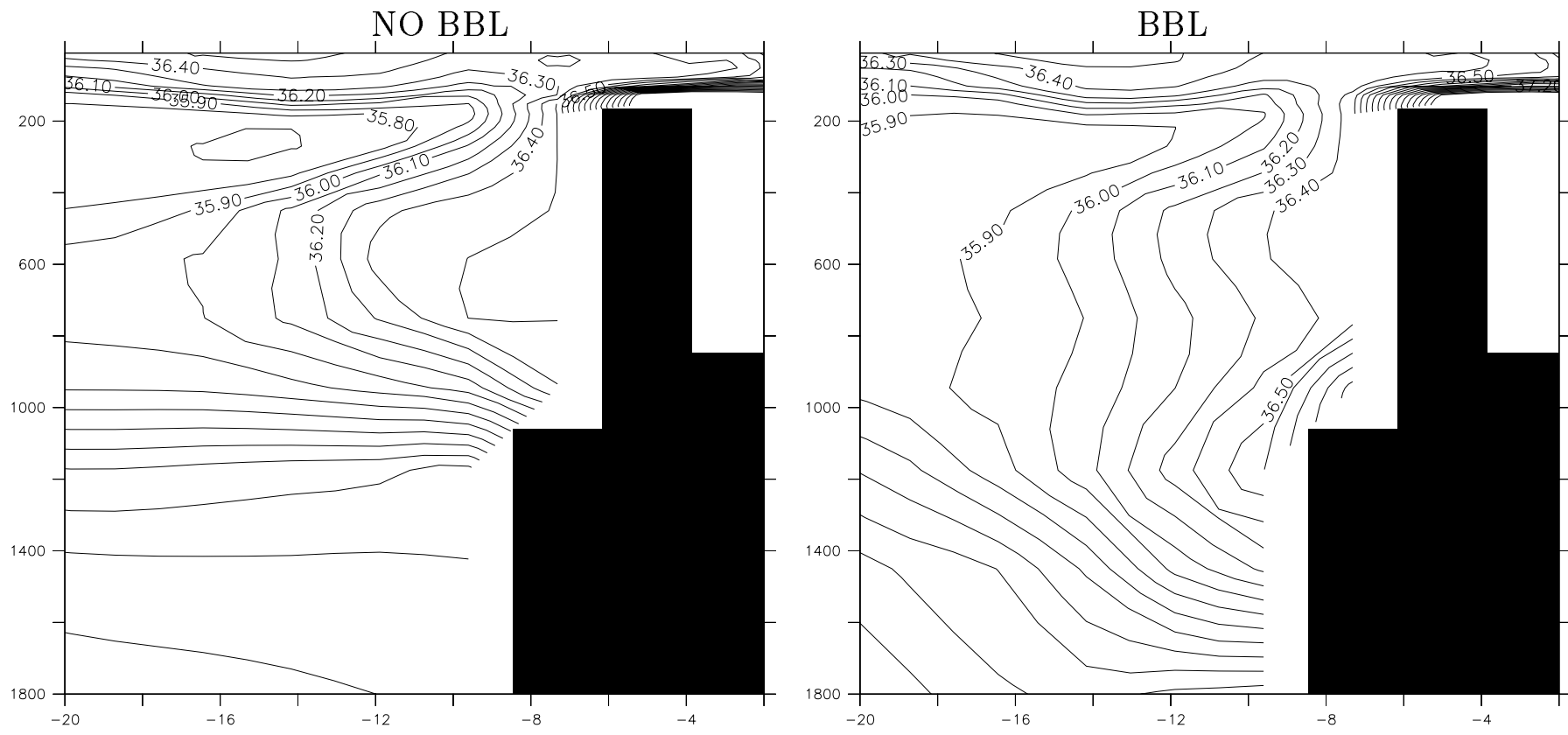

Figure 13: Mean salinity averaged over years 400-450 for the simulation without (left) and with (right) the BBL slope convection scheme. The depth-longitude section follows the orthogonal parallel closest to $36^{\circ} \mathrm{N}$ in the vicinity of the Gibraltar Strait outflow. Contour interval is 0.1 psu. Labels show depth (ordinate) and longitude (abscissa). 


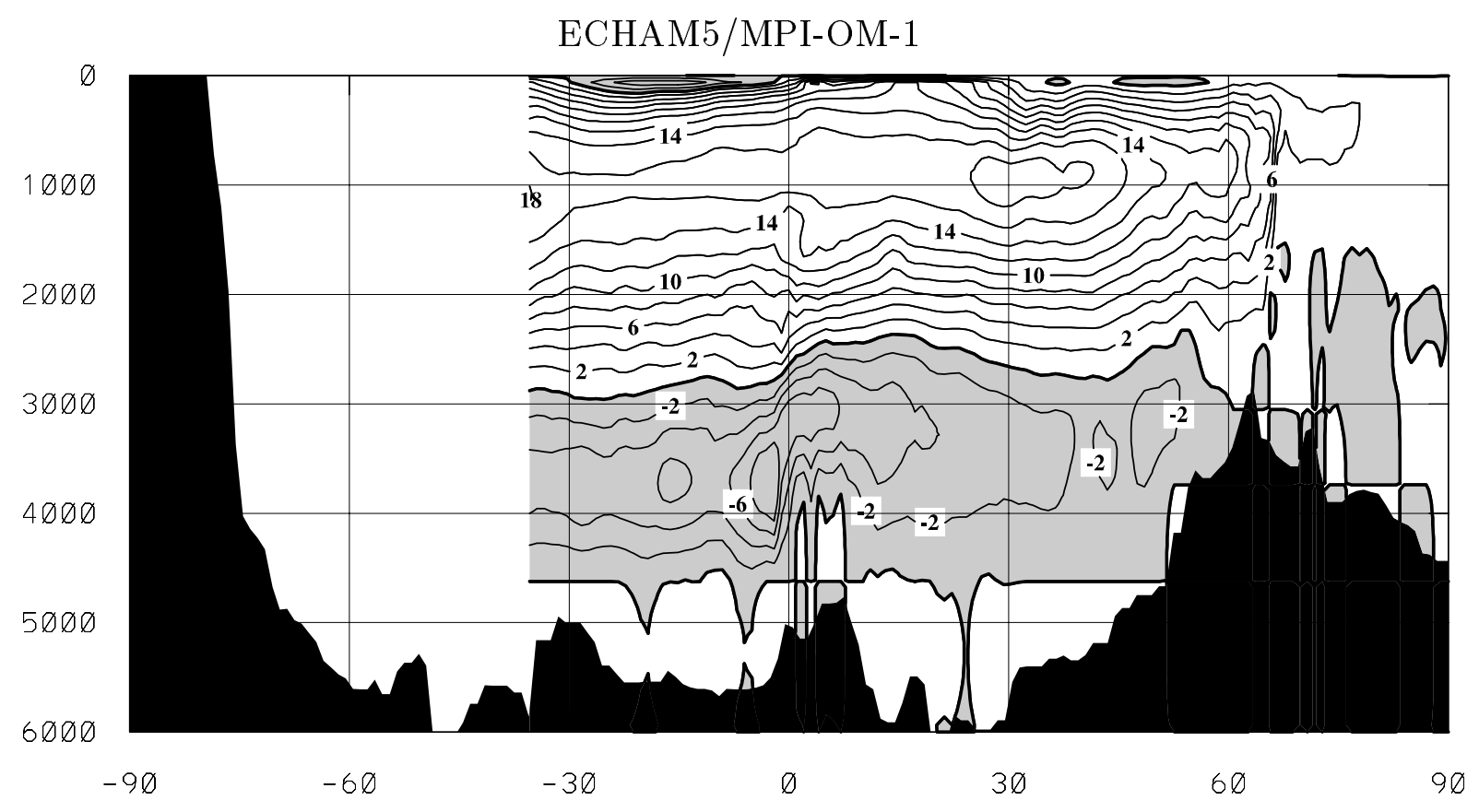

Figure 14: Atlantic meridional overturning streamfunction (Sv) averaged over the years 150-199 of the ECHAM5/MPI-OM-1 coupled atmosphere/ocean control simulation. Contour interval is $2 \mathrm{~Sv}$ with negative values shaded. Labels show depth (ordinate) and latitude (abscissa). 